\title{
Safety and efficacy of a COVID-19 treatment with nebulized and/or intravenous neutral electrolyzed saline combined with usual medical care vs. usual medical care alone: A randomized, open-label, controlled trial
}

\author{
IVAN DELGADO-ENCISO ${ }^{1,2}$, JUAN PAZ-GARCIA ${ }^{3}$, CARLOS E. BARAJAS-SAUCEDO $^{1}$, \\ KAREN A. MOKAY-RAMÍREZ ${ }^{1}$, CARMEN MEZA-ROBLES ${ }^{1,2}$, RODRIGO LOPEZ-FLORES ${ }^{2}$, \\ MARINA DELGADO-MACHUCA ${ }^{2}$, EFREN MURILLO-ZAMORA ${ }^{4}$, JOSE A. TOSCANO-VELAZQUEZ ${ }^{1}$, \\ JOSUEL DELGADO-ENCISO $^{5}$, VALERY MELNIKOV ${ }^{1}$, MIREYA WALLE-GUILLEN ${ }^{1,2}$, \\ HECTOR R. GALVAN-SALAZAR ${ }^{1,2}$, OSIRIS G. DELGADO-ENCISO ${ }^{1,5}$, ARIANA CABRERA-LICONA ${ }^{6}$, \\ EDUARDO J. DANIELEWICZ-MATA ${ }^{7}$, PABLO J. MANDUJANO-DIAZ ${ }^{\dagger}$, JOSÉ GUZMAN-ESQUIVEL ${ }^{1,5^{\prime}}$, \\ DANIEL A. MONTES-GALINDO ${ }^{1,2}$, HENRY PEREZ-MARTINEZ ${ }^{7}$, JESUS M. JIMENEZ-VILLEGAZ ${ }^{7}$, \\ ALEJANDRA E. HERNANDEZ-RANGEL ${ }^{1}$, PATRICIA MONTES-DIAZ ${ }^{8}$, IRAM P. RODRIGUEZ-SANCHEZ ${ }^{9}$, \\ MARGARITA L. MARTINEZ-FIERRO ${ }^{10}$, IDALIA GARZA-VELOZ ${ }^{10}$, DANIEL TIBURCIO-JIMENEZ ${ }^{1}$, \\ SERGIO A. ZAIZAR-FREGOSO ${ }^{1}$, FIDADELFO GONZALEZ-ALCARAZ ${ }^{7}$, \\ LAYDI GUTIERREZ-GUTIERREZ ${ }^{7}$, LUCIANO DIAZ-LOPEZ ${ }^{7}$, MARIO RAMIREZ-FLORES ${ }^{1}$, \\ HANNAH P. GUZMAN-SOLORZANO ${ }^{1}$, GUSTAVO GAYTAN-SANDOVAL ${ }^{2}$, \\ CARLOS R. MARTINEZ-PEREZ ${ }^{2}$, FRANCISCO ESPINOZA-GÓMEZ ${ }^{1}$, FABIÁN ROJAS-LARIOS ${ }^{1}$ \\ MICHAEL J. HIRSCH-MEILLON ${ }^{2}$, LUZ M. BALTAZAR-RODRIGUEZ ${ }^{1}$, ENRIQUE BARRIOS-NAVARRO ${ }^{1}$, \\ VLADIMIR OVIEDO-RODRIGUEZ ${ }^{2}$, MARTHA A. MENDOZA-HERNANDEZ ${ }^{1}$, \\ EMILIO PRIETO-DIAZ-CHAVEZ ${ }^{1}$ and BRENDA A. PAZ-MICHEL ${ }^{1,6}$

\footnotetext{
${ }^{1}$ Department of Molecular Medicine, School of Medicine, University of Colima, Colima 28040; ${ }^{2}$ Department of Research, Cancerology State Institute, Colima State Health Services, Colima $28085 ;{ }^{3}$ Department of Internal Medicine and Surgery, Union Hospital Center, Villa de Álvarez, Colima 28970; ${ }^{4}$ Department of Research, General Hospital of Zone No. 1 and Family Medicine Unit No. 19 IMSS, Villa de Alvarez, Colima 28984; 5 Department of Research, Foundation for Cancer Ethics, Education and Research of The Cancerology State Institute, Colima 28085; ${ }^{6}$ Department of Research, Esteripharma S.A. de C.V., Ciudad de México 03100; ${ }^{7}$ COVID-19 Respiratory Care Clinic INSABI Poliforum, Tuxtla Gutierrez, Chiapas 29040; ${ }^{8}$ Private Medical Office Xochitepec, Xochitepec, Morelos 62795; ${ }^{9}$ Laboratory of Molecular and Structural Physiology, School of Biological Sciences, Universidad Autónoma de Nuevo León, San Nicolas de los Garza, Nuevo León 66455; ${ }^{10}$ Molecular Medicine Laboratory, Academic Unit of Human Medicine and Health Sciences, Autonomous University of Zacatecas, Zacatecas 98160, México
}

Received March 4, 2021; Accepted May 11, 2021

DOI: $10.3892 / \mathrm{etm} .2021 .10347$

Correspondence to: Dr Brenda A. Paz-Michel, Department of Research, Esteripharma S.A. de C.V., 1582 Patricio Sanz, Colonia del Valle Centro, Ciudad de México 03100, México

E-mail: bpaz@esteripharma.com.mx

Abbreviations: ROS, reactive oxygen species; PASS, patient acceptable symptom state; RR, relative risk; CI, confidence interval; RPCEC, Cuban public registry of clinical trials; NSAIDs, nonsteroidal anti-inflammatory drugs; ARDS, acute respiratory distress syndrome; AST, aspartate aminotransferase; ALT, alanine aminotransferase; VAS, visual analog scale; CRP, C-reactive protein; ALP, alkaline phosphatase; NK, natural killer

Key words: COVID-19, neutral electrolyzed saline, SARS-CoV-2, reactive oxygen species, reactive chlorine species, immune system, inflammation, treatment
Abstract. Coronavirus disease 2019 (COVID-19) is currently the major public health problem worldwide. Neutral electrolyzed saline solution that contains reactive chlorine and oxygen species may be an effective therapeutic. In the present study, the treatment efficacy of intravenous and/or nebulized neutral electrolyzed saline combined with usual medical care vs. usual medical care alone was evaluated in ambulatory patients with COVID-19. A prospective, 2-arm, parallel-group, randomized, open-label, multi-center, phase I-II clinical trial including 214 patients was performed. The following two outcomes were evaluated during the 20-day follow-up: i) The number of patients with disease progression; and ii) the patient acceptable symptom state. Serial severe acute respiratory syndrome coronavirus 2 naso/oro-pharyngeal detection by reverse transcription-quantitative (RT-q) PCR was performed in certain patients of the experimental group. Biochemical and hematologic parameters, as well as adverse effects, were also evaluated in the experimental group. 
The experimental treatment decreased the risk of hospitalization by $89 \%$ [adjusted relative risk $(\mathrm{RR})=0.11,95 \%$ confidence interval (CI): $0.03-0.37, \mathrm{P}<0.001]$ and the risk of death by 96\% (adjusted $\mathrm{RR}=0.04,95 \% \mathrm{CI}$ : $0.01-0.42, \mathrm{P}=0.007$ ) and also resulted in an 18-fold higher probability of achieving an acceptable symptom state on day 5 (adjusted RR=18.14, 95\% CI: 7.29-45.09, $\mathrm{P}<0.001)$, compared with usual medical care alone. Overall, neutral electrolyzed saline solution was better than usual medical care alone. Of the patients analyzed, $>50 \%$ were negative for the virus as detected by RT-qPCR in naso/oro-pharyngeal samples on day 4 , with only a small number of positive patients on day 6. Clinical improvement correlated with a decrease in C-reactive protein, aberrant monocytes and increased lymphocytes and platelets. Cortisol and testosterone levels were also evaluated and a decrease in cortisol levels and an increase in the testosterone-cortisol ratio were observed on days 2 and 4 . The experimental treatment produced no serious adverse effects. In conclusion, neutral electrolyzed saline solution markedly reduced the symptomatology and risk of progression in ambulatory patients with COVID-19. The present clinical trial was registered in the Cuban public registry of clinical trials (RPCEC) database (May 5, 2020; no. TX-COVID19: RPCEC00000309).

\section{Introduction}

Coronavirus disease (COVID-19), caused by the severe acute respiratory syndrome coronavirus 2 (SARS-CoV-2), is currently the major public health problem worldwide $(1,2)$. Previous studies reported that the most common initial symptoms are systemic, upper respiratory symptoms and cough. Lower respiratory and gastrointestinal symptoms are less frequent and generally appear at the late stage of the disease (3). The symptoms, if present, with the longest duration are cough, loss of sense of smell or taste, sinus congestion, shortness of breath upon exertion, body aches and headache (3). A study on the time that COVID-19 patients require to achieve a usual state of health reported that 65 percent have returned to their usual state of health 7 days from the date of diagnosis, whereas $35 \%$ of patients had not returned to their usual state of health at 12-14 days after receiving a positive test result (4). Although most infections are self-limited, an estimated $15 \%$ of infected adults develop severe pneumonia that requires treatment with supplemental oxygen and hospitalization (5). However, the number of infected patients identified as having severe infection and requiring hospitalization varies among regions and countries, whether due to inherent conditions in the population (6) or to the strategy used in identifying individuals that are positive for the virus (7). In Mexico, $40.3 \%$ of confirmed cases are estimated to require hospitalization (8).

There are numerous experimental approaches for treating COVID-19. Initially, chloroquine appeared to be a promising treatment, but its lack of efficacy has since been demonstrated (9). Despite the numerous drugs that are currently recommended, such as nonsteroidal anti-inflammatory drugs (NSAIDs), corticoids, antivirals, antibiotics and proinflammatory cytokine (interleukin) modulators, no specific drug therapy has been proven to be effective against SARS-CoV-2, yet (10). Treatment is symptomatic and oxygen therapy is the first step in addressing respiratory impairment (1). Noninvasive and invasive mechanical ventilation may be necessary in cases of respiratory failure that is refractory to oxygen therapy (1).

COVID-19 symptomatology and manifestations depend on the degree of immune dysregulation caused by the virus, characterized by systemic inflammation and remote organ injury $(11,12)$. Viral infection is capable of producing an excessive immune reaction in the host. In severe cases, a reaction known as 'cytokine storm' occurs (1). A rapid and robust type I IFN-orchestrated response may lead to virus clearance, given that antiviral lymphocytes, such as natural killer (NK) cells, are activated and expanded. Conversely, late activation of innate immunity is usually associated with severe pathology that may lead to pneumonia, acute respiratory distress syndrome (ARDS), septic shock, multi-organ failure and, eventually, death (13). Different immune system alterations come together to produce severe disease. A key factor in the cytokine storm in COVID-19 is the elevation of monocytes, a circulating innate immune cell type producing IL-6 (14), combined with lymphocyte reduction that limits the systemic antiviral response $(15,16)$. Inefficient SARS-CoV-2 clearance by alveolar macrophages may promote excessive viral replication, leading to severe pathology that is accompanied by increased viral shedding and, in turn, viral transmissibility (13). In the present study, it was postulated that administration of intravenous and/or nebulized electrolyzed saline may aid in modulating the body's immune response to SARS-CoV-2, reducing symptomatology and preventing disease progression.

Electrolyzed saline is produced from a saline solution of sodium chloride, activated by a controlled process of electrolysis, producing reactive species of chlorine and reactive oxygen species (ROS). Significant examples of said reactive species are oxidant chlorine species, such as hypochlorous acid and oxidant ROS, such as hydrogen peroxide. Molecular hydrogen $\left(\mathrm{H}_{2}\right)$ is also produced (17). ROS are normally produced in the organism and have different physiological functions (18). Their most well-known activity is to control bacteria, parasites and viruses through the activity of cells of the innate immune response, macrophages and neutrophils that release ROS to structurally damage the invading pathogens, thus protecting the host from infection (19).

A series of studies have indicated that, in addition to the primordial innate immune response, ROS are secondary messengers in processes of exacerbated inflammation control and tissue repair in a process known as redox signaling. Redox signaling is ROS-dependent and the immune response varies, according to ROS concentrations and exposure time (19-23). Different studies have indicated that ROS are able to activate and repair phenotypes, such as M2 macrophages and regulatory $\mathrm{T}$ cells, acting as potentiators of the humoral immune response $(24,25)$. ROS have been indicated to mediate the communication between the different cells of the immune system, such as polymorphonuclear cells, neutrophils, macrophages, antigen-presenting cells, B cells and T cells (23-26). Specifically, hypochlorous acid may act as a coadjuvant and adaptive immune response stimulator by modifying antigen proteins and increasing their recognition, processing and presentation by antigen-presenting dendritic cells (27). In addition, ROS have an important role in later stages of B-cell activation by promoting the sustained signaling of B-cell antigen receptors, thus favoring antibody production (28). 
Numerous studies have also suggested that $\mathrm{H}_{2}$ has beneficial effects in diverse animal models and human diseases (29). Its oral administration in an animal model limited the increase of IL-6 and tumor necrosis factor-alpha, producing a potent antioxidant and anti-inflammatory effect (30).

Therefore, the present study was designed to randomly select patients with COVID-19 receiving usual medical care and compare the safety and efficacy of two treatments: Usual medical care combined with electrolyzed saline [administered intravenously and/or through inhalation of the aerosol (nebulization), with dose escalation] and usual medical care alone (control).

\section{Materials and methods}

Study design. A prospective, randomized, single-blind, 2-arm, parallel-group, open-label, phase I-II clinical trial was performed between May and December 2020 and carried out according to the consolidated standards of reporting trials (CONSORT) statement guidelines for randomized controlled trials (31). The study aimed to evaluate the safety and efficacy of electrolyzed saline for preventing disease progression and it was approved by the ethics committee of the School of Medicine of the Universidad de Colima (Colima, México; April 8, 2020), and written informed consent was obtained from all of the participants. The trial was performed in accordance with the principles of the Declaration of Helsinki and the International Conference on Harmonization-Good Clinical Practice guidelines. The present clinical trial was registered in the Cuban public registry of clinical trials (RPCEC) database (May 5, 2020; no. TX-COVID19: RPCEC00000309).

Study subjects. The inclusion criteria were as follows: Males and non-pregnant females aged $\geq 18$ years, presenting with COVID-19 and a positive diagnosis of SARS-CoV-2 by reverse transcription-quantitative (RT-q) PCR, who had a medical consultation due to their illness and were indicated for at-home ambulatory treatment. Women of reproductive age, without permanent contraceptive methods and sexually active agreed to utilize effective non-hormonal contraceptive measures during the study period and for at least 15 days after the final drug administration of the study. Exclusion criteria were pregnant or breastfeeding females and patients presenting with any of the following conditions prior to the diagnosis of COVID-19: Cancer, ischemic heart disease, chronic decompensated systemic disease, creatinine 1.25 times higher than the normal value or creatinine clearance $<50 \mathrm{milliliters} / \mathrm{min}$ (Cockcroft-Gault method), blood hemoglobin $<10 \mathrm{~g} / \mathrm{dl}$, drug addiction (illegal drugs) or known liver disease with a doubling of liver function test values [aspartate aminotransferase (AST), alanine aminotransferase (ALT), alkaline phosphatase (ALP) or bilirubin]. In addition, the following elimination criteria were applied: Patients who decided to drop out of the study, patients who at any point of the study, presented with severe toxicity (grade 3 or higher, according to the Common Terminology Criteria for Adverse Events v5.0, US Department of Health and Human Services) (32), that was attributable to the administration of the experimental drug.

The physicians participating in the project identified candidates from primary and secondary healthcare centers (public or private) in the Mexican states of Colima, Chiapas and Morelos (in Colima: Regional University Hospital from the Health Ministry of the State of Colima, Colima Hospital, General Hospital of Zone 1 of the IMSS Colima, Medical Center Union Clinic, San Francisco Clinic; in Chiapas: Poliforum COVID-19 Respiratory Care Clinic; in Morelos: Private practice medical office Xochitepec). The physicians asked the patients for their permission, once they were at home, for the researchers to call them by telephone, requesting their participation in the study. Prior to said phone call, the candidates were randomly allocated to the experimental group (electrolyzed saline + usual medical care) or the control group (usual medical care alone). Randomization was performed using computer-generated random allocation cards. In that manner, the patients were directly asked to participate in one of the non-blinded groups. The inclusion process was performed by researchers who did not participate in the evaluation of the results. Prior to entering the study, all of the patients were receiving usual treatment under the care of their family physician or specialist. When asked to participate in the study, the patients selected for the electrolyzed saline group were told they would receive an experimental treatment in addition to their usual medical care, as well as have sign and symptom follow-up and undergo certain laboratory tests. The patients receiving usual medical care alone (control group) were asked to participate in the study, with follow-up of signs and symptoms performed by telephone. All of the patients were advised that they would continue to be under the supervision of their regular physician or healthcare institution and that the research team would in no way modify or limit any intervention that their physician, or they themselves, considered pertinent, such as going to the emergency service if there were any alarming symptoms.

Neutral electrolyzed saline. The experimental treatment consisted of an aqueous saline solution of sodium chloride, activated by a controlled process of electrolysis (patent no. MX330845B), and thus resembled activated saline, electrolyzed saline or electrolyzed water. It had a neutral $\mathrm{pH}(6.0-7.5)$ and its active ingredient was $0.002 \%$ of active species of chlorine and oxygen. The good manufacturing practices for intravenous electrolyzed saline (HOMEOSTECH ${ }^{\circledR}$ ) also met the required processes for sterile injectable products (33). As an intravenous (IV) electrolyzed saline, its formulation was $17.12 \mathrm{mEq} / \mathrm{l}$ of sodium chloride and $0.38 \mathrm{mM}$ of active species of chlorine and oxygen. The vials utilized were 5-ml ampules, and the name and composition were indelibly printed on each one. The electrolyzed saline was provided by Esteripharma S.A. de C.V as an experimental (not commercial) product.

When the randomized patient was in the electrolyzed saline group, he or she was included in a dose escalation with overdose control design, as has previously been reported (34). Dose level 1 consisted of nebulizations (inhalation of the mist, produced by a nebulizer provided with a mask for inhalation therapy). The nebulizations were indicated 4 times a day for 10 days. They were performed by placing $5 \mathrm{ml}$ of electrolyzed saline in the nebulizer chamber (Nebucor, type MOD. P-100; Neb S.A. de C.V.) and continuing the nebulization until the content was used up (10-15 min). The nebulizations were performed following the recommendations of the American College of Allergy, Asthma and Immunology (35), the British 
Lung Foundation (36), the Asthma Society of Ireland (37) and the British Thoracic Society (38).

The IV dosing began with a dose within a safe range, previously established in a phase I clinical trial conducted at the Instituto Estatal de Cancerología de Colima for the treatment of chikungunya (manuscripts in preparation; clinical trial registration number RPCEC00000226. The initial applications were $15 \mathrm{ml}$ (dose level 2) once a day for 7 days, with successive increases to $20 \mathrm{ml} /$ day (dose level 3), $30 \mathrm{ml} /$ day (dose level 4), $30-40 \mathrm{ml} /$ twice daily (dose level 5), $40 \mathrm{ml} /$ day (dose level 6), $80 \mathrm{ml} /$ day (dose level 7) and $150 \mathrm{ml} /$ day (dose level 8). All applications were made every $24 \mathrm{~h}$ for 7 days or 10 days only if diarrhea, myalgia, arthralgia or body temperature $>37.5^{\circ} \mathrm{C}$ was present on the seventh day of treatment. Dose level 5 was the exception, where applications were made every $12 \mathrm{~h}$ for 3 (dose level 5.1), 6 (dose level 5.2) or 9 days (dose level 5.3) (Fig. S1). Nebulizations with electrolyzed saline solution were always added to all IV treatment regimens. The dose-limiting toxicity was not achieved at any dose level.

The electrolyzed saline solution was diluted in one-third of its volume with physiological saline solution $(0.9 \%$ of $\mathrm{NaCl})$ ( $1 \mathrm{ml}$ physiological solution for every $2 \mathrm{ml}$ oelectrolyzed saline), immediately prior to its application, for the case of dose levels 2-6. The solution was administered IV as a bolus (passing it in 1-2 min). For dose levels 7 and 8, $100 \mathrm{ml}$ of normal saline solution $(0.9 \%$ of $\mathrm{NaCl})$ were withdrawn from a $250-\mathrm{ml}$ bottle and the appropriate volume of electrolyzed saline for each regimen was added, under sterile conditions using a Class-II laminar flow hood BSL-2. The whole solution mixture was administered in $1 \mathrm{~h}$, with applications once a day using a heparinized peripheral venous catheter for its intermittent use.

When COVID-19 symptoms of nausea, vomiting and/or diarrhea occurred, $30 \mathrm{ml}$ oral electrolyzed saline was added, 4 times a day, for as long as gastrointestinal symptoms lasted, plus 2 more days after the symptoms disappeared. The oral route of electrolyzed saline has been shown to be safe and has been used to treat epidemic diarrhea virus infection in preclinical trials $(39,40)$. In patients with oropharyngeal ulcerations and/or intense throat irritation (causing intense pain), the indication was to gargle with $10 \mathrm{ml}$ electrolyzed saline 6 times a day and swallow the solution after gargling with it. This was performed for the number of days necessary for the pain to decrease to 4 or less on the $0-10$ visual analog scale (VAS). The oral pathway was indicated in 17 patients and gargling was indicated in 25 . These indications were added during the protocol to rapidly evaluate them without compromising the original trial outcomes, a procedure that has been considered adequate in previous scientific reviews (41). The indication was based on intended uses previously authorized (local treatment of throat infections and sore) by the Mexican Federal Commission for the Protection against Sanitary Risks (COFEPRIS) of a similar product (Estericide Bucofaríngeo, Reg. No. 1003C2013 SSA; Esteripharma).

Usual medical care. The patients receiving only usual medical care continued with the usual treatment prescribed by their family physician or specialist. Usual care is the care the targeted patient population would be expected to receive as part of normal practice (42). This is a valid strategy as a reference treatment in clinical trials, including various therapy trials against COVID-19 (43-45). It consisted of the administration of paracetamol, NSAIDs, steroids, azithromycin, chloroquine, ivermectin, and/or antiviral drugs, anticoagulants, etc.; the patients were instructed to return to the emergency service if there was respiratory difficulty or worsening of symptomatology. The researchers did not intervene in drug prescription or lifestyle indications (usual medical care).

Outcome measures and follow-up. There were 3 co-primary endpoints. The first was the number of patients with disease progression, defined as hospitalization or death. The second primary endpoint was the patient acceptable symptom state (PASS), defined as the value of symptoms the patient considered to be well-being thresholds of pain and function. In the present study, the most widely used anchoring question to identify PASS cut-off points was incorporated, which as follows: 'Taking into account all your daily activities, do you consider your current state satisfactory in relation to pain level and functional impairment?' with response options being 'Yes' or 'No' (46-48). Treatment success was defined as no disease progression or a PASS according to the answer in the affirmative test on days 1 to 20 of follow-up. The third endpoint was the change from the baseline in the patient overall self-assessment or the severity score, which was determined by the response to the following question: 'Considering all the ways in which illness and health conditions may affect you at this time, please indicate how you are doing?' with the response options measured on the 0-10 VAS, from 'very well' (score of 0 ) to 'very poorly' (score of 10) (49). This question was validated using the Routine Assessment of Patient Index Data 3, previously used to determine the activity of autoimmune diseases, degenerative diseases, such as osteoarthritis (50) and infectious diseases with a strong component of general malaise, such as chikungunya fever (51). That endpoint is similar to the symptom severity score (self-assessed using a 10-point VAS) recently used in a clinical trial that evaluated the efficacy of hydroxychloroquine in non-hospitalized patients with COVID-19, where 0 indicated 'no symptoms' and 10 indicated 'severe symptoms' (52). The patients were also classified at baseline according to disease severity, as directed by the World Health Organization (WHO) interim clinical management guidance; as mild, moderate, severe or critical disease (53). In addition, the concepts of asymptomatic patients (0 major symptoms and 0 minor symptoms) and pauci-symptomatic patients (0 major symptoms and 1-2 minor symptoms) were considered, as previously defined (major symptoms: Fever $>37.8^{\circ} \mathrm{C}$ and new persistent cough; minor symptoms: Hoarse voice, non-persistent cough, sore throat, runny or stuffy nose, shortness of breath, wheezing, headache, muscle aches, nausea and/or vomiting and/or diarrhea and loss of sense of taste or smell) (54).

The secondary endpoints were changes from the baseline in different types of body pain (arthralgia, myalgia, headache and sore throat), or more precisely, the difference from the values at enrollment on all days of follow-up. Pain was measured on the 0-10 VAS (55). Intensity of pain was recorded, from 'no pain' (score of 0 ) to 'worst pain imaginable' (score of 10) $(55,56$ ). Patients completed the previously validated fatigue VAS (scale of $0-10)(57)$, which poses the questions of: 'How much of a 
problem has unusual fatigue or tiredness been for you today' and was anchored from 0 (fatigue is not a problem) to 10 (fatigue is a major problem). Daily coughing episodes were reported by the patient on a numerical scale from 0 to 20 . If there were more than 20 episodes, they were registered as 20 . Dyspnea was determined once a day through the Borg scale, from 0 to 10 , according to which 0 indicates no dyspnea and 10 extremely severe dyspnea (58). Nausea, vomiting, diarrhea, dizziness, conjunctivitis, rhinorrhea, exanthema, skin rash and loss of sense of smell or taste were recorded as present or absent for each day of follow-up. Adverse events were monitored by the researchers through anamnesis and abnormal routine laboratory test results. Follow-up was performed for at least 20 days or until an endpoint was reached (cure or death). Daily follow-up was suspended in the hospitalized patients, and from the day of hospital admission, their registers were considered lost data and were not considered in the analysis from that day forward, with the exception of the PASS, the result of which was reported as a negative acceptable symptom state from then onwards. However, the general aspects of those patients were registered, such as hospitalization and outcome (cure or death).

Serial detection of SARS-CoV-2. In 10 patients from the experimental group treated with electrolyzed saline, nasopharyngeal and oropharyngeal samples were collected with swabs in $2.5 \mathrm{ml}$ of viral transport medium, immediately prior to starting treatment and on days 2, 4, 6 and 14, and stored at $-80^{\circ} \mathrm{C}$ until processing. Viral RNA was isolated utilizing TRIzol (Invitrogen; Thermo Fisher Scientific, Inc.) according to the manufacturer's protocol and SARS-CoV-2 testing was performed through SYBR green-based reverse transcription-quantitative (RT-q) PCR using the previously described methodology (59). That procedure was not performed on any of the patients in the control group.

Evaluation of hematologic and serologic parameters. In the experimental group, changes in hematologic parameters were evaluated at baseline, at $48 \mathrm{~h}$ (day 2) and on days 4 , 6, 9 and 14. The complete blood count was evaluated using Sysmex XP-300 (Roche ${ }^{\circledR}$ ) equipment, the biochemical tests for kidney function and liver function were performed using Cobas c111 (Roche ${ }^{\circledR}$ ) equipment and the serum concentration of testosterone and cortisol were determined by immunofluorescence with the $\mathrm{iCHROMA} \mathrm{(Boditech} \mathrm{Med} \mathrm{Inc.)} \mathrm{equipment.}$ The testosterone-cortisol ratio was calculated by dividing the two hormone levels, both expressed in $\mathrm{nm} / \mathrm{l}$ (60). Thirty patients with any type of steroidal or hormonal treatment were excluded from this analysis. Systemic inflammation markers (erythrocyte sedimentation rate and C-reactive protein) were also evaluated and rapid staining of blood smears with staining kits (Hycel) were performed to quantify the following: i) Reactive lymphocytes, also called virocytes; ii) large granular lymphocytes, a representation of NK cells or cytotoxic T lymphocytes; iii) activated monocytes; and iv) monocytes with aberrant nuclei (clumped chromatin) and basophilic cytoplasm $(14,61,62)$.

Blinding. Only the researchers that evaluated treatment effectiveness through the VAS, PASS and other endpoints instruments answered by the patients, as well as those that performed the statistical analyses, were blinded. The personnel who provided the treatments were different from the personnel in charge of evaluating the effectiveness of the treatments.

Sample size. The sample size calculation was based on the number of patients that had disease progression (hospitalization or death). Progression in $10 \%$ of patients in the experimental group and $35 \%$ of subjects in the control group was predicted. Those figures were based on local data from the Mexican city of Colima, according to which $43 \%$ of confirmed patients were hospitalized, according to health authority reports (63). A total of 32 patients from each group were needed to reach the required statistical power $(0.8)$ when the statistical analysis was performed at the level of a one-tailed alpha-value of 0.05 . At the end of the study, the statistical power for detecting a difference between two distinct groups was calculated (one-tailed alpha $=0.05$ ), utilizing the number of patients with disease progression, resulting in $99.2 \%$.

Statistical analysis. Values are expressed as the mean \pm standard deviation (for data with a normal distribution), median with 25 and 75 th percentiles (interquartile range) for data with a non-normal distribution or percentages. Normality of distribution of data was first determined using the Kolmogorov-Smirnov test and the equality of variances was confirmed using Levene's test. Parametric data with a normal distribution [e.g., body mass index (BMI) or age] were compared between groups utilizing Student's t-test. Categorical variables were compared using the Fisher's exact test or likelihood ratio $\chi^{2}$ test. To compare continuous variables with a non-normal distribution or data in ordinal scale between two groups, the Mann-Whitney U-test was applied to independent samples and the Wilcoxon signed-rank test was applied to matched samples. For the oxygen saturation parameter, the change from baseline was used to observe the absolute differences between the evaluation periods, calculated through the value after intervention minus the value at baseline, in each patient, which is an acceptable manner for analyzing trial results with baseline and after the beginning of treatment measurements (64). To test for a significant difference in means over time in blood parameters, repeated-measures ANOVA was used, followed by Dunnett's post-hoc test (any time-point vs. baseline). The Jonckheere-Terpstra test was used to determine differences in symptom severity between dose levels on different days, followed by pairwise comparisons between groups using Dunn's test. Kaplan-Meier analyses were performed to compare survival and the log-rank test was applied to determine significant differences between groups. Binary logistic regression analyses were employed to determine the probability of hospitalization or achieving PASS on day 5 (binomial outcome: Yes or no) with the experimental treatment, compared with the usual medical care. Data were summarized as relative risk (RR) with 95\% confidence interval (CI) and P-value, adjusted for age, sex, BMI, baseline of oxygen saturation $\left(\mathrm{SpO}_{2}\right)$, diabetes, hypertension, progression time, baseline severity and other relevant variables. Binomial regression is considered the most adequate choice for estimating RRs in multivariate analyses (65-67). Pearson's correlation coefficients (r) were calculated for bivariate 
correlation between numeric and normally-distributed parameters (C-reactive protein, monocytes, platelets, lymphocytes, cortisol and testosterone-cortisol ratio); while Spearman's rank correlation coefficients (r) were generated when any of the above parameters was correlated with the patient symptom severity score (ordinal scale). Significant correlations were discussed based on the P-value.

The statistical analysis was performed using the SPSS version 20 software (IBM Corp.), with the exception of the number needed to treat (NNT), which was calculated using MedCalc v17.7.2 software (MedCalc Software bvba), and sample size and statistical power, which were calculated using the online calculator software by HyLown Consulting LLC to compare 2 proportions: 2-sample, 1-sided (http:// powerandsamplesize.com/Calculators/Compare-2-

Proportions/2-Sample-1-Sided) (68). $\mathrm{P}<0.05$ was considered to indicate statistical significance. Sample size and statistical power were calculated for a one-tailed test. The remaining analyses were two-tailed tests.

\section{Results}

Patients and symptoms. A total of 242 patients were randomized and screened. Finally, 113 patients in the experimental group and 104 patients in the control group agreed to participate in the study. In the experimental group, 3 patients discontinued the intervention, leaving this group with 110 patients for the analysis (Fig. S1). Gender Ratio in the analyzed patients was 101.88 male per 100 female subjects. The mean ages of the experimental and control patients were $45.5 \pm 14.1$ and $41.8 \pm 15.4$ years old, respectively $(\mathrm{P}=0.073)$ (Table I). The major clinical characteristics and prescribed drugs are presented in Table I, exhibiting homogeneous characteristics between the groups (experimental vs. control) at the beginning of the study. The symptoms at baseline were also similar (Table SI).

The clinical severity distribution of all patients with SARS-CoV-2 infection in the present study according to the WHO interim clinical management guidance (53) was as follows: Mild (79.9\%), moderate (8.9\%) and severe $(11.2 \%)$. The median reported symptom severity score, according to a self-assessment 10-point VAS, was 7 (interquartile range, 5 to 8 ), and the median number of COVID-19-compatible symptoms was 8 (interquartile range, 7 to 9 symptoms). None of the patients was asymptomatic or pauci-symptomatic, since all of them required specialized therapy with a health care professional. Therefore, in spite of the absence of any clinical or imaging signs suggestive of pneumonia, the patients were symptomatic.

Evaluation of clinical improvement and disease progression. The results were analyzed through two data grouping strategies. The control group (usual medical care) was compared with the experimental group, which included all dose levels of the experimental therapy. The other analyses compared the different dose levels of therapy between one another and with the control group, to determine the most efficacious therapeutic dose. In the control group, $19.2 \%$ of the patients had disease progression (hospitalization or death), compared with $7.3 \%$ of the patients receiving the experimental therapy, with a statistically significant difference in the Kaplan-Meier analysis with log-rank test $(\mathrm{P}=0.008)$. Fig. 1A shows that the group of patients that received electrolyzed saline had fewer hospitalizations, compared with the patients that received only the usual medical care. Regarding only the patients that were hospitalized, the time interval from inclusion in the study to hospitalization was lower in the control group compared with that in the experimental therapy group $(4.5 \pm 1.3$ days vs. $7.0 \pm 4.0$ days, respectively; $\mathrm{P}=0.018$ ) (see Table II). Death occurred in $8.7 \%$ of all the patients in the control group and $1.8 \%$ of the patients in the experimental group $(\mathrm{P}=0.025$, Kaplan-Meier analysis with log-rank test) (Table II). Fig. 1B shows the proportion of patients achieving PASS. The mean time to PASS in the control group was $9.0 \pm 0.6$ days, compared with $5.1 \pm 0.4$ days in the experimental therapy group $(\mathrm{P}<0.001$, Kaplan-Meier analysis with log-rank test). With respect to the different treatment schemes with electrolyzed saline, their effect on the severity of symptoms was dose level-dependent, with IV + nebulized administration being better than nebulized administration alone, but nebulized administration was better than usual medical care alone (Fig. 2).

The multivariate analysis indicated that in patients who received the experimental treatment, in addition to usual medical care, the risk of becoming hospitalized was reduced by $89 \%$ (adjusted $\mathrm{RR}=0.11,95 \% \mathrm{CI}$ : $0.03-0.37, \mathrm{P}<0.001$ ), the risk of death was reduced by $96 \%$ (adjusted $\mathrm{RR}=0.04,95 \%$ CI: $0.01-0.42, \mathrm{P}=0.007$ ) and the probability of achieving an acceptable symptom state on day 5 was 18 -fold higher (adjusted RR=18.14, 95\% CI: 7.29-45.09, $\mathrm{P}<0.001$ ), compared to usual medical care alone. The analysis also indicated the relationship between baseline characteristics of patients (such as sex, age, relevant comorbidities) and the probability of achieving an acceptable symptom state, or being hospitalized, or dying from COVID-19. It was observed that the presence of diabetes, advanced age or an $\mathrm{SpO}_{2}<94 \%$ were factors associated with an increased risk of being hospitalized or dying from the disease (Table SII). With the experimental treatment, the NNT to prevent hospitalization of a patient was $8.3(95 \%$ CI: 4.7-32.6), one out of two patients treated with electrolyzed saline achieving an acceptable symptom state on day 5 or earlier (NNT=2.4; 95\% CI: 1.90-3.52).

When the patients were classified according to the severity of their disease (Table II), it was observed that for patients with mild disease, treatment with electrolyzed saline significantly reduced the time to reach an acceptable symptom state compared with usual medical care alone $(4.2 \pm 0.4$ days vs. $7.2 \pm 6$ days, $\mathrm{P}<0.001)$. Furthermore, for patients with moderate/severe disease, electrolyzed saline combined with usual medical care vs. usual medical care alone achieved a large decrease in the proportion of hospitalized patients (19\% vs. $88 \%$ ) and deaths (7.7\% vs. $41 \%$; Table II).

Progression of signs and symptoms. Table SI provides an analysis of the symptoms with respect to their presence or absence at the beginning of the study and throughout the follow-up. The number of patients with those symptoms at baseline did not differ between groups (except for sore throat and nausea, which were higher in the control group). The number of patients with fatigue, myalgia, fever, vomiting, conjunctivitis, dizziness, anosmia and/or ageusia was significantly reduced in the experimental group compared with the control 
Table I. Major clinical characteristics of the participating subjects at the time of enrollment and usual prescribed drugs.

\begin{tabular}{|c|c|c|c|}
\hline Clinical characteristic & Control $(n=104)$ & Experimental $(n=110)$ & P-value \\
\hline Female sex $(\%)$ & 52.9 & 46.4 & $0.412^{\mathrm{a}}$ \\
\hline Age (years) & $41.8 \pm 15.4$ & $45.5 \pm 14.1$ & $0.073^{\mathrm{b}}$ \\
\hline BMI $\left(\mathrm{kg} / \mathrm{m}^{2}\right)$ & $29.6 \pm 4.7$ & $28.6 \pm 5.1$ & $0.136^{\mathrm{b}}$ \\
\hline Diabetes $(\%)$ & 15.4 & 17.3 & $0.717^{\mathrm{a}}$ \\
\hline High blood pressure (\%) & 15.4 & 18.2 & $0.715^{\mathrm{a}}$ \\
\hline Asthma $(\%)$ & 2.9 & 7.3 & $0.216^{\mathrm{a}}$ \\
\hline Smoking (\%) & 11.5 & 12.7 & $0.837^{\mathrm{a}}$ \\
\hline Progression time ${ }^{c}$ & $4.1 \pm 2.6$ & $4.7 \pm 3.6$ & $0.142^{\mathrm{b}}$ \\
\hline Body temperature $\left({ }^{\circ} \mathrm{C}\right)$ & $37.3 \pm 1.0$ & $37.4 \pm 0.8$ & $0.718^{\mathrm{b}}$ \\
\hline$\% \mathrm{SpO}_{2}$ & $95.1 \pm 2.8$ & $94.3 \pm 3.1$ & $0.077^{\mathrm{b}}$ \\
\hline $\mathrm{SpO}_{2}<94 \%(\%)$ & 35.6 & 41.8 & $0.400^{\mathrm{a}}$ \\
\hline Degree of dyspnea & $1.2 \pm 1.5$ & $1.2 \pm 1.4$ & $0.956^{\mathrm{b}}$ \\
\hline Symptom severity ${ }^{\mathrm{d}}$ & $6.8 \pm 2.2$ & $6.4 \pm 2.3$ & $0.153^{\mathrm{e}}$ \\
\hline Number of symptoms ${ }^{f}$ & $8(7-9)$ & $8(6-9)$ & $0.109^{\mathrm{e}}$ \\
\hline Disease severityWHO (\%) & & & $0.390^{\mathrm{g}}$ \\
\hline Mild & 83.7 & 76.4 & \\
\hline Moderate & 6.7 & 10.9 & \\
\hline Severe & 9.6 & 12.7 & \\
\hline \multicolumn{4}{|l|}{ Treatments } \\
\hline Number & $2.8+1.6$ & $2.7+1.5$ & $0.822^{\mathrm{a}}$ \\
\hline Paracetamol (\%) & 56.7 & 50.0 & $0.522^{\mathrm{a}}$ \\
\hline NSAIDs $(\%)$ & 57.7 & 60.0 & $0.291^{\mathrm{a}}$ \\
\hline Ivermectin (\%) & 9.6 & 13.6 & $0.373^{\mathrm{a}}$ \\
\hline Chloroquine (\%) & 7.7 & 3.6 & $0.325^{\mathrm{a}}$ \\
\hline Antibiotics (\%) & 45.2 & 45.5 & $0.368^{\mathrm{a}}$ \\
\hline Antivirals (\%) & 22.1 & 14.5 & $0.345^{\mathrm{a}}$ \\
\hline Antihistamines (\%) & 14.4 & 13.6 & $0.591^{\mathrm{a}}$ \\
\hline Steroids $(\%)$ & 30.8 & 27.3 & $0.479^{\mathrm{a}}$ \\
\hline Anticoagulants (\%) & 14.4 & 11.8 & $0.430^{\mathrm{a}}$ \\
\hline Vitamins $(\%)$ & 16.3 & 13.6 & $0.476^{\mathrm{a}}$ \\
\hline
\end{tabular}

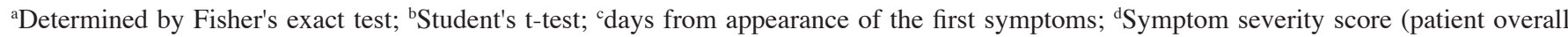
self-assessment) using a 10-point visual analog scale; ${ }^{\mathrm{e}}$ Mann-Whitney U-test; ${ }^{\mathrm{f}}$ number of Coronavirus disease 2019-compatible symptoms, expressed as the median and interquartile range; glikelihood ratio $\chi^{2}$ test. WHO, disease severity as directed by the World Health Organization (53); BMI, body mass index, underweight $(<18.5)$, normal (18.5-24.9), overweight (25.0-29.9) and obese $(\geq 30.0)$; $\mathrm{SpO}_{2}$, oxygen saturation determined by a pulse oximeter on the right-hand middle finger; NSAIDs, nonsteroidal anti-inflammatory drugs; antivirals, oseltamivir or amantadine; antibiotics, azithromycin, clarithromycin or levofloxacin.

group during the follow-up time, but not at the baseline. This suggests that a proportion of patients were spared of certain symptoms during their illness due to the experimental treatment. With respect to patients with one particular symptom, the last day from enrolment they presented with fever $(0.7 \pm 1.1$ vs. $2.1 \pm 1.5, \mathrm{P}<0.001)$, headache $(3.7 \pm 3.5$ vs. $7.3 \pm 4.3, \mathrm{P}<0.001)$, fatigue $(6.0 \pm 3.8$ vs. $8.6 \pm 4.3, \mathrm{P}<0.001)$, myalgia ( $4.4 \pm 3.5$ vs. $6.0 \pm 3.4, \mathrm{P}=0.001)$, retro-orbital eye pain $(2.1 \pm 2.9$ vs. $3.9 \pm 3.6$, $\mathrm{P}=0.001)$, chills $(1.6 \pm 2.3$ vs. $2.9 \pm 3.1, \mathrm{P}=0.013)$, rhinorrhea (2.8 \pm 3.4 vs. $4.5 \pm 4.6, \mathrm{P}<0.001)$, nausea $(1.8 \pm 2.5$ vs. $4.4 \pm 4.5$, $\mathrm{P}<0.001)$, vomiting $(0.7 \pm 2.0$ vs. $1.7 \pm 2.4, \mathrm{P}=0.026)$, dizziness $(1.6 \pm 2.2$ vs. $3.8 \pm 4.6, \mathrm{P}<0.001)$, conjunctivitis $(0.9 \pm 2.2$ vs $3.0 \pm 4.1, \mathrm{P}<0.001)$, anosmia $(5.7 \pm 3.2$ vs. $8.9 \pm 4.8, \mathrm{P}<0.001)$, ageusia $(3.6 \pm 3.4$ vs. $7.7 \pm 5.2, \mathrm{P}<0.001)$ or diarrhea $(4.0 \pm 3.1$ vs.
$5.9 \pm 3.9, \mathrm{P}=0.025)$ was significantly lower in the experimental group vs. the control group (Table $\mathrm{SI}$ ).

A quantitative analysis of the symptom severity score (patient overall self-assessment) was performed and score/values on various scales (10-point VAS) for fatigue, headache, sore throat, retro-orbital eye pain, myalgia, body temperature (degrees centigrade) and oxygen saturation $\left(\mathrm{SpO}_{2}\right)$ exhibited a significant improvement in the experimental group at $24 \mathrm{~h}$ from the start of treatment (day 1) as compared with the control group. There was also a decrease in cough and heart rate on day 3 and arthralgia on day 9 (Table SIII).

Oral administration of electrolyzed saline to treat gastrointestinal symptoms was indicated in 17 patients, while 25 were prescribed gargling to treat a sore throat. All of these patients 
A Usual medical care (control)

- Usual medical care+All variants of experimental therapy

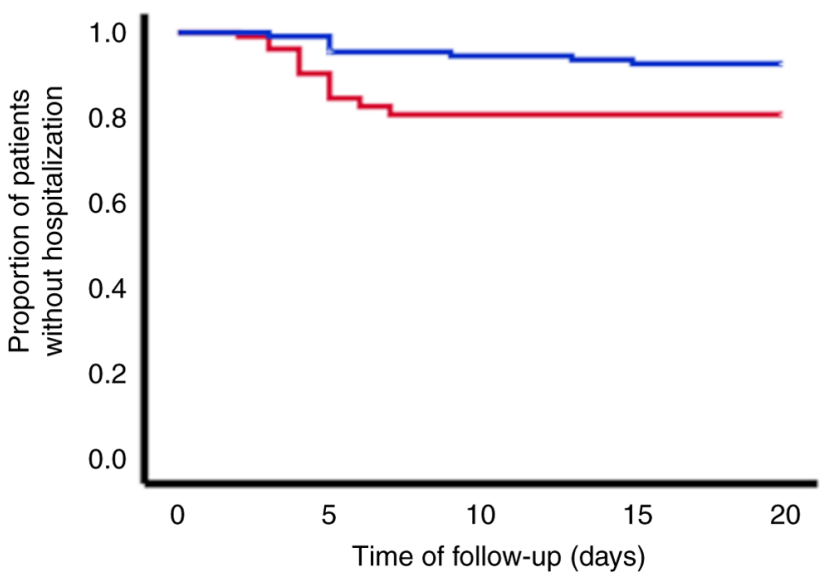

$\mathrm{B}-$ Usual medical care (control) - Usual medical care+All leves of experimental therapy

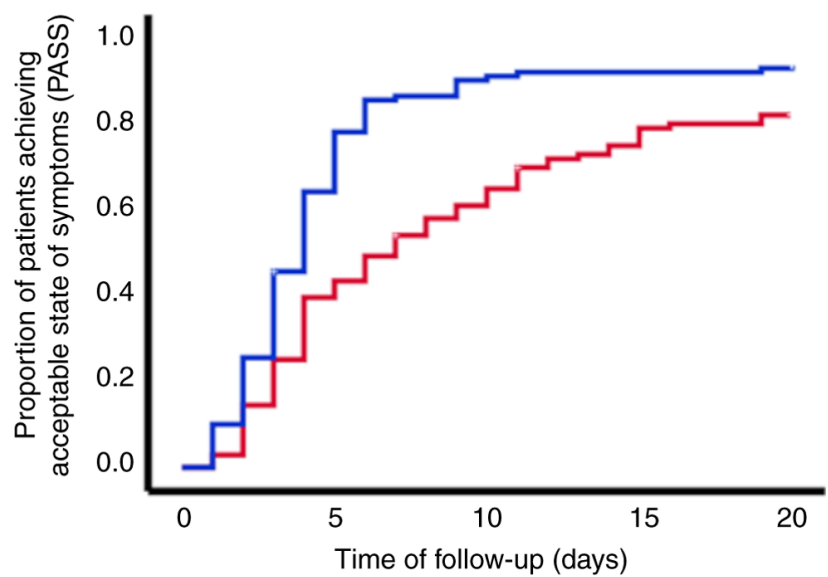

Figure 1. Kaplan-Meier curves indicating the progression of patients. (A) Shows that the group of patients that received electrolyzed saline had fewer hospitalizations (7.3\%), compared with the patients that received only usual medical care (19.2\%) ( $\mathrm{P}=0.008)$. (B) Shows the proportion of patients achieving PASS The mean time to PASS in the control group was $9.0 \pm 0.6$ days, compared with $5.1 \pm 0.4$ days in the experimental therapy group $(\mathrm{P}<0.001)$. The log-rank test was applied to compare curves.

reported a reduction or disappearance of symptomatology within 24-48 h of administration.

SARS-CoV2 detection during treatment with electrolyzed saline. Serial virus detection in nasopharyngeal and oropharyngeal samples at baseline and on days $2,4,6$ and 9 was performed in 10 patients. As presented in Table III, $>50 \%$ of patients were negative for the virus on day 4 , with only a $20 \%$ of positive patients on day 6 and $0 \%$ on day 9 . In the majority of cases, the test for the virus was negative on the days after having achieved a PASS. Of note, patient P30 achieved a PASS on days 3-5, but reported an unacceptable state on day 6 and a PASS on day 7 and thereafter. This suggests that a PASS does not always accompany the elimination of the virus (positive patients up to day 6) and that there may be a relapse of symptoms. Patient P29 achieved a PASS on day 2, was negative for the virus until day 6, when she was once again positive. Patients P29 and P30 were a couple who were living together, without implementing any physical distancing measures during follow-up, signifying that the probable cause of positivity on day 6 of P29 was due to transitory reinfection or contamination derived from living with a patient still presenting with viremia (P30).

Inflammatory and immune response markers. The erythrocyte sedimentation rate was a parameter that remained elevated during the entire follow-up (Table SIV), with no significant differences between the baseline value and the 14 days of follow-up included. This was due to the fact that the maximum value reached by each patient exhibited marked variations over the days of follow-up. There was a significant decrease in C-reactive protein (CRP) $48 \mathrm{~h}$ after starting the treatment, with average reductions of 43 and $73 \%$ at $48 \mathrm{~h}$ and 4 days after the beginning of treatment, respectively (Table SIV). Considering the baseline CRP values and symptom severity score (possible score of $0-10$ resembling very well to very poor) as $100 \%$ and the relative value on the subsequent days of evaluation, there was a significant correlation between $\mathrm{CRP}$ and the clinical progression of the patients $(\mathrm{r}=0.301, \mathrm{P}<0.001)$. A greater decrease in CRP was associated with a greater reduction in the patient symptom severity score (reduced severity) (results not shown).

In relation to the baseline level of hematopoietic cells, there was a significant increase (within normal values) of total leukocytes on days 6, 9 and 14 . The quantity of total lymphocytes gradually increased on days 2 and 4, until reaching significantly elevated levels on day 6 (Table SIV). The reactive lymphocytes exhibited a significant elevation on day 2 of follow-up, reducing and losing its statistical significance with respect to the baseline value on subsequent days. The quantity of large granular lymphocytes (a representation of NK cells) began to rise gradually, with a mean of $65 \pm 33 \times 10^{3} / \mu 1$ at baseline, until they were significantly elevated on day 6 , with $155 \pm 78 \times 10^{3} / \mu 1(\mathrm{P}=0.006)$, after which they began to decrease again. The quantity of total monocytes exhibited a tendency to gradually decrease, with no significant differences. However, the aberrant monocytes (larger cells, with clumped chromatin and basophilic cytoplasm) decreased significantly, with a mean of $450 \pm 357 \times 10^{3} / \mu 1$ at baseline, to $229 \pm 232 \times 10^{3} / \mu 1$ after $48 \mathrm{~h}(\mathrm{P}=0.003)$. That decrease was sustained during the entire follow-up. The activated monocytes exhibited no significant changes with respect to baseline values during the follow-up. Another change was an increase in platelets, which, although they remained within normal ranges, they rose consistently throughout the follow-up, having significantly high values on days 6-14 (Table SIV).

The quantity of total monocytes correlated with the CRP levels $(\mathrm{r}=0.466, \mathrm{P}<0.001)$. Of note, the quantity of aberrant monocytes correlated with the patients' overall self-assessment score (symptom severity score; $r=0.478, \mathrm{P}=0.001$ ), signifying that the more the aberrant monocytes decreased, the better the patient felt (results not shown). The gradual and significant increase of platelets after treatment correlated with several beneficial aspects, such as increased lymphocytes and clinical 
Table II. Outcomes in the experimental and control groups of patients with Coronavirus disease 2019 according to WHO disease severity classification.

\begin{tabular}{lccc}
\hline A, All patients & & & \\
\hline Item & Experimental (n=110) & Control (n=104) & $<0.001$ \\
\hline Days until PASS & $5.1 \pm 0.4$ & $9.0 \pm 0.6$ & $<0.001$ \\
PASS on day 5 (\%) & 79.8 & 39.4 & 0.008 \\
Hospitalized (\%) & 7.3 & 19.2 & 0.018 \\
Days to be hospitalized & $7.0 \pm 4.0$ & $4.5 \pm 1.3$ & 0.024 \\
Death (\%) & 1.8 & 8.7 & 0.902 \\
Days to death & $19.5 \pm 2.1$ & $18.5 \pm 10.1$ & \\
\hline
\end{tabular}

B, Mild disease

\begin{tabular}{lccr}
\hline Item & Experimental $(\mathrm{n}=84)$ & Control (n=87) & P-value \\
\hline Days until PASS & $4.2 \pm 0.4$ & $7.2 \pm 6$ & $<0.001$ \\
PASS on day 5 (\%) & 84.5 & 46.0 & $<0.001$ \\
Hospitalized (\%) & 3.6 & 5.7 & 0.380 \\
Days to be hospitalized & $6.2 \pm 3.8$ & $4.0 \pm 0.7$ & 0.250 \\
Death (\%) & 0.0 & 2.3 & 0.257 \\
Days to death & NA & $27.5 \pm 3.5$ & NA \\
\hline
\end{tabular}

C, Moderate and severe disease

\begin{tabular}{lccr}
\hline Item & Experimental $(\mathrm{n}=26)$ & Control $(\mathrm{n}=17)$ & P-value \\
\hline Days until PASS & $7.8 \pm 1.4$ & $18.5 \pm 1.0$ & $<0.001$ \\
PASS on day 5 (\%) & 65.4 & 5.9 & $<0.001$ \\
Hospitalized (\%) & 19.2 & 88.2 & $<0.001$ \\
Days to be hospitalized & $7.8 \pm 4.3$ & $4.7 \pm 1.4$ & 0.025 \\
Death (\%) & 7.7 & 41.2 & 0.012 \\
Days to death & $19.5 \pm 2.1$ & $15.2 \pm 8.9$ & 0.548
\end{tabular}

Severity of disease was according to the WHO interim clinical management guidance (53). P-values were determined using Fisher's exact test, except days for PASS, which was compared using log-rank test for comparison of Kaplan-Meier analysis. PASS, patient acceptable symptom state; WHO, World Health Organization. Days to be hospitalized and days to die: Time elapsed since the patient begins his treatment within the study until his hospitalization or death occurs. NA: Not analyzed because $n=0$ in one group.

improvement of the patients, given that the quantity of platelets correlated with the total lymphocytes $(\mathrm{r}=0.341, \mathrm{P}=0.004)$ and with the patients' overall self-assessment score $(\mathrm{r}=-0.398$, $\mathrm{P}=0.001$ ) (results not shown).

Testosterone and cortisol levels. The concentration of cortisol significantly decreased on day 2 . On the other hand, the testosterone concentration increased, although there was no statistical significance. A significant increase in the testosterone-cortisol ratio was present on days 2 and 4 (Table SIV). The gradual and significant decrease in cortisol after treatment correlated with the decrease in $C R P$ values $(r=0.202, P=0.033)$, and with the increase in lymphocytes $(\mathrm{r}=-0.319, \mathrm{P}=0.001)$, monocytes $(\mathrm{r}=-0.251$, $\mathrm{P}=0.005)$ and platelets $(\mathrm{r}=-0.172, \mathrm{P}=0.046)$, whereas the increase in the testosterone-cortisol ratio correlated with the decrease in activated monocytes ( $\mathrm{r}=-0.272, \mathrm{P}=0.019)$ (results not shown).
Adverse events and toxicity. A total of two patients did not tolerate the nebulization due to a burning sensation in the throat and stopped using it on the second day but continued with IV applications. In addition, four patients reported transitory dizziness lasting for $10 \mathrm{~min}$ after the IV application of the experimental solution; this was self-limited and managed by lying down. Furthermore, five patients reported mild pain in the first $5 \mathrm{~cm}$ of the vein path where the solution was applied after the entire treatment scheme. This mild pain was self-limited and not accompanied by any other signs or symptoms; it disappeared within 1 to 2 days after the end of the treatment. No other adverse events were reported. There were no abnormal or unexpected alterations due to COVID-19 in the serum levels of liver enzymes (ALT, AST, lactate dehydrogenase and ALP), bilirubin, albumin, glucose, creatinine, uric acid, urea or complete blood count (Table SIV). 


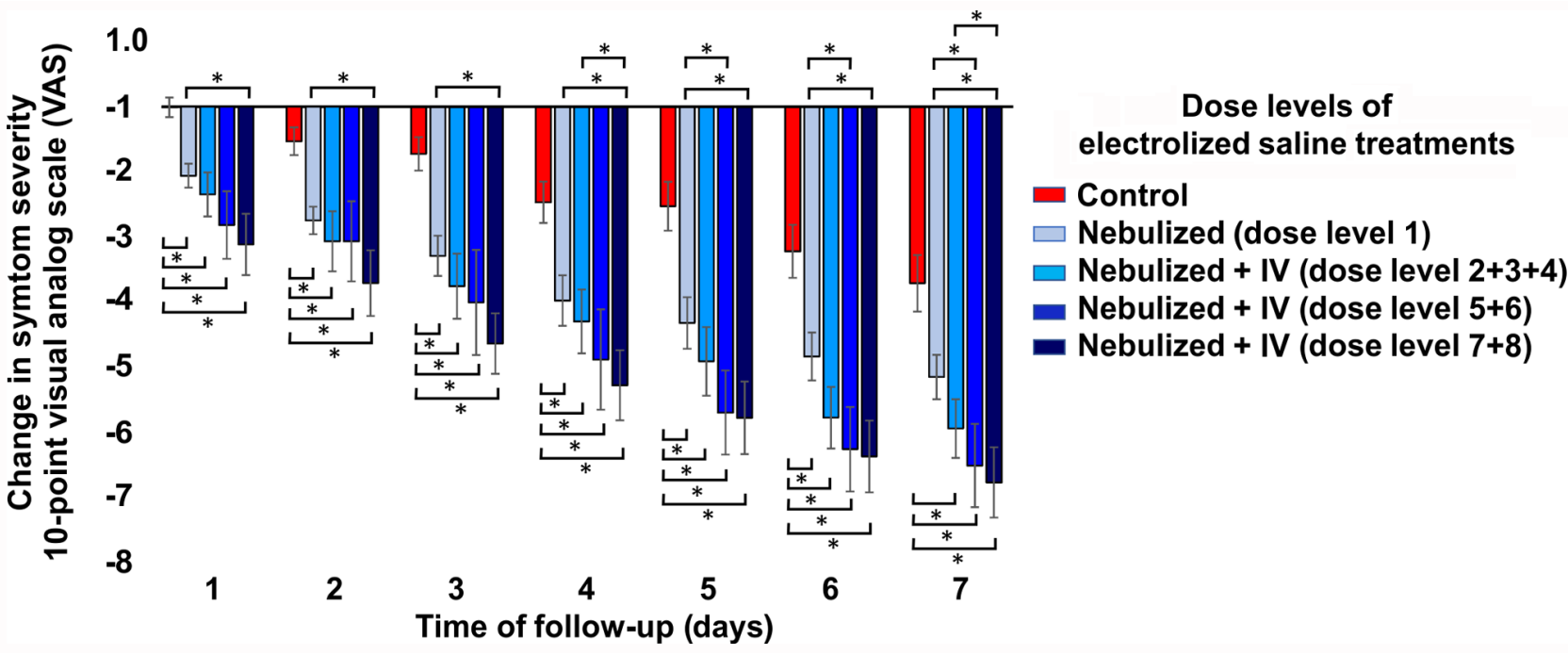

Figure 2. Change in the severity of the general symptoms with respect to the baseline score according to the different dose levels. All dose levels of electrolyzed saline performed significantly better in reducing the severity of symptoms than usual medical care alone, while the higher dose levels $($ dose levels $7+8)$ were significantly better than just nebulization (dose level 1). Compared with just nebulization, dose levels $5+6$ only significantly reduced symptoms on days 6 and 7. Symptom severity was determined by an overall self-assessment of the patient using a 10-point visual analog scale, where the change is the result of the value of a given day minus its baseline value. The Jonckheere-Terpstra test followed by pairwise comparisons between groups with Dunn's test indicated differences in symptom severity between dose level groups at all measurement time-points. "P<0.05. Groups: Control, usual medical care ( $\mathrm{n}=104$ ); experimental groups, treatment with usual medical care plus electrolyzed saline at different doses: 1-nebulization (n=35); 2/3/4-nebulization + IV administration of 15,20 or $30 \mathrm{ml}$ per day, respectively $(\mathrm{n}=32)$; 5/6-nebulization + IV administration of $30 \mathrm{ml}$ twice a day or $40 \mathrm{ml}$ once a day, respectively ( $=16$ ); and 7/8-nebulization + IV administration of 80 or $150 \mathrm{ml}$ per day, respectively $(\mathrm{n}=27)$. IV, intravenous.

\section{Discussion}

In ambulatory patients with COVID-19 receiving the usual medical care, additional administration of electrolyzed saline reduced the probability of disease progression (hospitalization and death) by $89 \%$, compared with ambulatory patients treated with usual medical care alone. Different signs and symptoms, such as fatigue, headache, sore throat, retro-orbital eye pain, myalgia, body temperature and oxygen saturation, improved significantly after the first $24 \mathrm{~h}$ of experimental therapy.

By adding neutral electrolyzed saline to the usual medical care, it was possible to significantly reduce the time to reach an acceptable state of symptoms in all patients, particularly in those with mild and severe disease. The greatest benefit of the treatment is observed in patients with moderate/severe disease, where a major change was observed in the proportion of patients who were hospitalized (19\% vs. $88 \%$ ) or died $(7.7 \%$ vs. $41 \%)$, compared with the patients under usual medical care alone. The treatment was more effective when high doses $(\geq 30 \mathrm{ml})$ of IV electrolyzed saline were administered. All dose levels of electrolyzed saline were significantly better in reducing the severity of symptoms than the usual medical care alone and the higher dose levels (dose level $7+8$ ) were significantly better than just the nebulizations (dose level 1). The beneficial effects of the administration of electrolyzed saline may generally be associated with the mechanisms related to the following: i) Reduction of inflammatory processes; and ii) elimination of the virus by the immune system and by direct contact with the electrolyzed saline. The proposed mechanism of action is illustrated in Fig. 3.

The improvement of signs and symptoms correlated with a significant reduction of systemic inflammation, with a $>40 \%$ decrease of CRP levels at $48 \mathrm{~h}$ after starting treatment. There was also a correlation between CRP levels and the quantity of monocytes. Said reduction, particularly of aberrant monocytes, was significant at $48 \mathrm{~h}$ and lasted to the end of follow-up, strengthening the hypothesis of the modulating effect of the systemic administration of electrolyzed saline on inflammation, reflected in the clinical improvement of the patients. In the early stage of COVID-19, CRP levels have previously been indicated to reflect the extent of lung lesions and disease severity, providing an important clinical evaluation index (69). Monocytes and pulmonary monocytes have a key early role in the progression to severe COVID-19 by promoting a cytokine storm, ARDS and disseminated peripheral tissue damage (14). The aberrant monocytes that decreased after the experimental treatment were larger than normal monocytes, with clumped chromatin and basophilic cytoplasm (62). Morphologically altered monocytes, particularly larger ones, are associated with a hyperinflammatory gene expression profile and with admission to intensive care units in patients with type 2 diabetes with COVID-19 (70). By contrast, with the reduction in the quantity and relative percentage of aberrant monocytes seen after the experimental treatment, the number of normal monocytes increased. Patients with a high number of normal monocytes have a better outcome, with earlier recovery and discharge from hospital (71). This result has been postulated to be relatively specific for COVID-19, as a similar pattern in patients with other viral illnesses, such as H1N1, influenza, HIV or hantavirus, has not been observed (71).

In relation to improved immune function, through the administration of electrolyzed saline, a gradual increase in total lymphocytes and large granular lymphocytes (a representation of NK cells) was observed, reaching a significantly elevated level on day 6. Lymphocytes have a crucial role in virus clearance after a viral infection. On the one hand, 
Table III. SARS-CoV-2 detection over time in nasopharyngeal samples of 10 patients in the experimental group.

\begin{tabular}{|c|c|c|c|c|c|c|c|c|c|c|c|c|}
\hline \multirow[b]{3}{*}{ Patient no..$^{\dagger}$} & \multirow{3}{*}{$\begin{array}{l}\text { Dose } \\
\text { level }\end{array}$} & \multirow{3}{*}{$\begin{array}{c}\text { Age } \\
\text { (years) }\end{array}$} & \multirow{3}{*}{$\begin{array}{l}\text { Progression } \\
\text { time } \\
\text { (days) }^{\mathrm{a}}\end{array}$} & \multicolumn{3}{|c|}{ Baseline severity } & \multirow{3}{*}{$\begin{array}{l}\text { Days } \\
\text { until } \\
\text { PASS }\end{array}$} & \multirow{2}{*}{\multicolumn{5}{|c|}{ SARS-CoV2 detection result (days }} \\
\hline & & & & & & & & & & & & \\
\hline & & & & Score $^{\mathrm{b}}$ & $\mathrm{WHO}^{\mathrm{c}}$ & symptoms $^{\mathrm{d}}$ & & Baseline & 2 & 4 & 6 & 9 \\
\hline P1-M & 1 & 45 & 3 & 3 & Mild & 5 & 4 & Pos. & Pos. & Neg. & Neg. & Neg. \\
\hline P12-F & 2 & 48 & 1 & 8 & Severe & 7 & 3 & Pos. & Pos. & Neg. & Neg. & Neg. \\
\hline P18-M & 3 & 46 & 3 & 9 & Mild & 8 & 5 & Pos. & Pos. & Pos. & Neg. & Neg. \\
\hline P19-M & 3 & 18 & 2 & 2 & Mild & 3 & 2 & Pos. & Pos. & Neg. & Neg. & Neg. \\
\hline P21-F & 4 & 29 & 3 & 5 & Mild & 7 & 3 & Pos. & Neg. & Neg. & Neg. & Neg. \\
\hline P22-M & 4 & 34 & 6 & 10 & Moderate & 9 & 3 & Pos. & Pos. & Pos. & Neg. & Neg. \\
\hline $\mathrm{P} 29-\mathrm{Fe}$ & 4 & 40 & 1 & 6 & Mild & 8 & 2 & Pos. & Neg. & Neg. & Pos. & Neg. \\
\hline P30-M & 5 & 43 & 1 & 8 & Mild & 9 & 7 & Pos. & Pos. & Pos. & Pos. & Neg. \\
\hline P39-M & 4 & 41 & 4 & 6 & Mild & 6 & 1 & Pos. & Neg. & Neg. & Neg. & Neg. \\
\hline P40-F & 5 & 65 & 6 & 6 & Mild & 7 & 2 & Pos. & Pos. & Pos. & Neg. & Neg. \\
\hline $\begin{array}{l}\text { Percentage of } \\
\text { positivity (\%) }\end{array}$ & & & & & & & & 100 & 70 & 40 & 20 & 0 \\
\hline
\end{tabular}

'Patient code, followed by the letter ' $M$ ' for male, or ' $F$ ' for female. 'Progression time, days from the appearance of the first symptoms; 'symptom score (patient overall self-assessment), using a 10-point visual analog scale, from 'very well' (0) to 'very poorly' (10); 'disease severity was defined according to the WHO (53); 'number of Coronavirus disease 2019-compatible symptoms; ${ }^{\mathrm{e}}$ partner of P30, living together during entire follow-up. PASS, patient acceptable symptom state; WHO, World Health Organization; Neg., negative; Pos., positive; SARS-CoV-2, severe acute respiratory syndrome coronavirus-2.

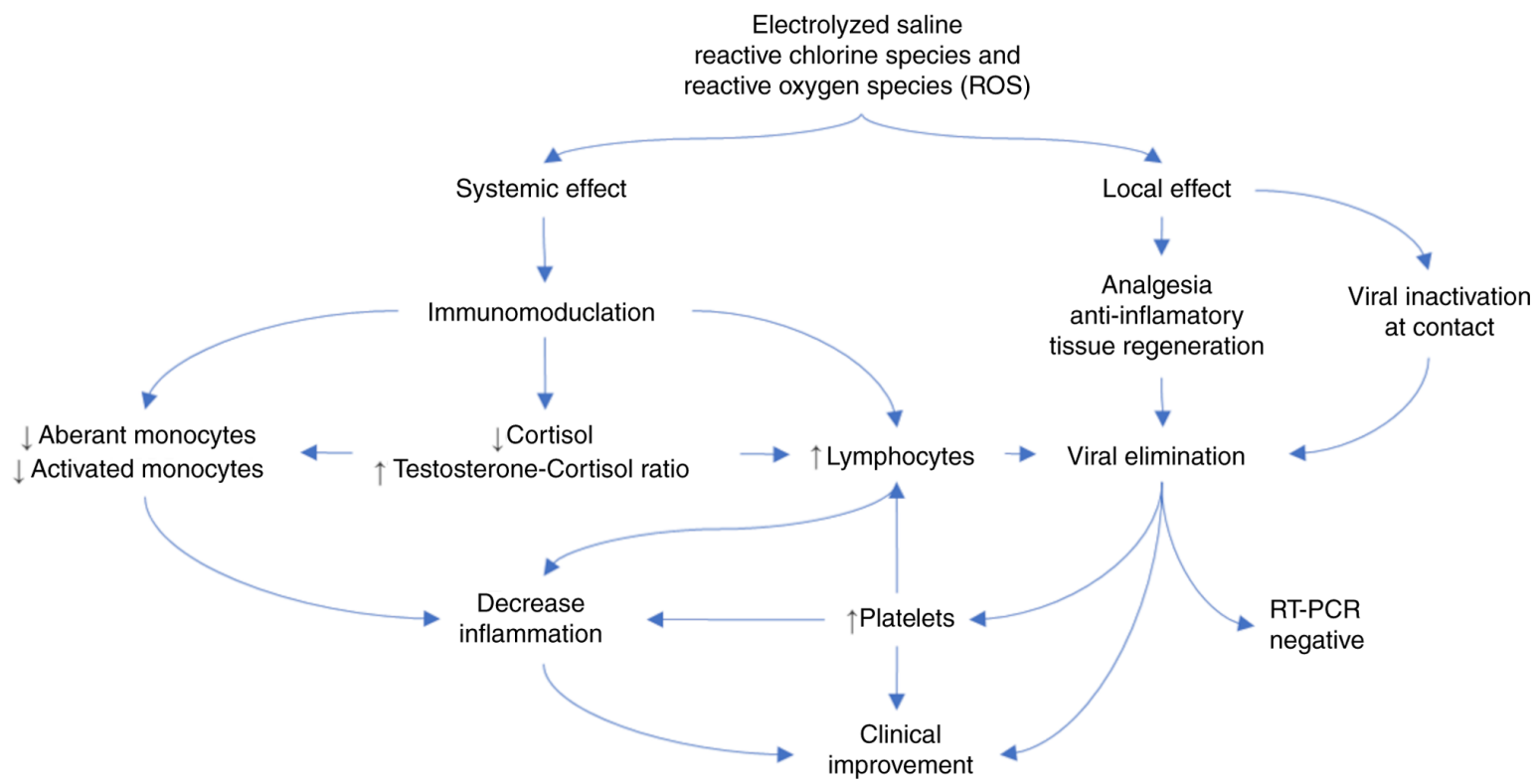

Figure 3. Proposed mechanism of action of the electrolyzed saline in patients with Coronavirus disease 2019. The systemic effect, generated mainly by intravenous application, has an immunomodulatory effect that reduces inflammation, with a reduction in aberrant and activated monocytes, as well as an increase in lymphocytes that help eliminate the virus. An increase in platelets and the testosterone-cortisol ratio, with a reduction in cortisol, contribute to this process. A local effect in the airways and digestive tract generates an anti-inflammatory, analgesic and tissue regeneration effect, with the inactivation of the virus by contact. All of these mechanisms contribute to clinical improvement.

NK cells eliminate virally infected cells via degranulation, receptor-mediated apoptosis and antibody-dependent cell-mediated cytotoxicity (72). On the other hand, the humoral immune response, primarily mediated by the production of antibodies by plasma B cells (B lymphocyte-derived cells), has a role in the neutralization of the virus (73). In line with the results of the present study, the lymphocyte count and the number of NK cells have been postulated to correlate with disease severity and may serve as a tool for identifying patients with a more severe clinical presentation of SARS and COVID-19 $(61,69,74)$. A lymphocyte count of $<1.5 \times 10^{9} / 1$ may be useful in predicting the severity of clinical outcomes (75). 
Even though T lymphocytes were not specifically identified in the present study, the large granular lymphocytes observed are a type of $\mathrm{T}$ lymphocyte $(14,61,62)$. Previous studies have indicated that the time of recovery of the T-lymphocyte count was fairly consistent with the clinical course (73). Patients with severe disease, but who recovered, the value of $\mathrm{T}$ lymphocytes was reported to begin to increase after 15 days of treatment, finally returning to normal levels after 25 days of treatment (73). By contrast, the level of T lymphocytes in severely ill patients and that finally deceased, continued to fall until they succumbed to the disease (73). That behavior concurred with the variation in the number of the large granular lymphocytes observed in the present study, in which that special type of lymphocyte increased on day 6 of treatment, in accordance with the clinical improvement of the majority of patients, and began to decrease in quantity on day 9 . The speed with which the process of elevation and reduction in those cells took place should be considered.

Another relevant aspect was the constant and significant increase in platelets after treatment with electrolyzed saline. Yang et al (76) recently demonstrated an association between reduced platelets and mortality in patients with COVID-19. Yang et al (76) correctly interpreted those results as follows: i) A 'higher' platelet count for an illness as severe as COVID-19 is unusual and likely points towards liver activation and thrombopoietin release; ii) the lung-specific entry of SARS-CoV-2 suggests that the lung megakaryocytes, in response to liver thrombopoietin, locally produce a large number of platelets to help with the defense of the host; iii) the reduction of platelets in patients with severe disease may be due to the fact that the platelets are being consumed to form pulmonary thrombi, which occurs when multiple efforts (including those of the platelets) to stop the infection have not succeeded and blocking the viral invasion has become necessary; and iv) Yang et al (76) also indicated that mortality decreased with the increase of the platelet count, suggesting the thrombotic process has abated and platelets are no longer consumed into the clot. In addition, platelets also have an anti-inflammatory function by regulating macrophage activity, regulatory $\mathrm{T}$ cells and secreting pro-resolving mediators (77). All of those observations concur with the results of the present study, according to which the increase in platelets correlated with an increase in total lymphocytes and clinical improvement in the patients (a lower patient overall self-assessment score).

Cortisol and testosterone are hormones related to immune system regulation (78). The increase in testosterone detected in the present study (although not statistically significant) is in agreement with the result of a recent study reporting that low testosterone levels are associated with immune system deficiencies and greater severity of COVID-19 (79). Likewise, low levels of cortisol, as detected in the present study, correlated with increased lymphocytes, which may contribute to a better antiviral response by the body. It has recently been indicated that high cortisol levels are associated with a greater risk of death of patients with COVID-19 (80). Similarly, the present study reported an increase in the testosterone-cortisol ratio on days 2 and 4 after the beginning of treatment. This is a parameter not previously studied in patients with COVID-19, to the best of our knowledge. This increase was correlated with a reduction in activated monocytes, which may help reduce the systemic inflammatory process. Monocyte activation was abnormal and contributes to the COVID-19 cytokine storm by releasing massive amounts of pro-inflammatory cytokines $(14,81)$.

The influence of testosterone and cortisol on monocytes has been previously reported. In patients with diabetes with hypogonadism, testosterone therapy reduced inflammatory activation of monocytes (82). It has also been indicated that cortisol signaling through the mineralocorticoid receptor, under oxidative stress, may promote monocyte inflammatory activation $(83,84)$; thus, a reduction in cortisol would also be favoring the reduction of activated monocytes, particularly in the context of rising testosterone levels. Furthermore, based on the assumption that free testosterone is a marker of anabolism, while cortisol is indicative of catabolism, it has been suggested that an increase in the testosterone-cortisol ratio is favorable for protein anabolism $(60,85)$, which may be beneficial in patients with COVID-19.

Electrolyzed saline, also known as electrolyzed water, has important antiseptic properties (86) and may be used directly on contaminated tissues or fluids $(87,88)$. Thus, in addition to the immunomodulatory effect produced when administered systemically, it may inactivate the new coronavirus by degradation of the envelope and nucleocapsid proteins $(89,90)$, when administered locally, without dilution to the lungs and throat, via nebulization and/or gargling, as it has been previously demonstrated for multiple viruses (87-90). However, the present study was the first to reveal the remarkable immunomodulating effect of electrolyzed saline administered systemically at the proper concentration of active species of chlorine and oxygen, acting to control and limit COVID-19 disease. Of note, all of the results of the present study concur with the proposed mechanism of rapid elimination of the virus from the respiratory tract, occurring within days, with negative virus test results in 60 and $80 \%$ of the patients on days 4 and 6 , respectively.

Local administration of electrolyzed saline to the throat to control pain or its oral intake to control the gastrointestinal symptoms of nausea, vomiting or diarrhea, were successful in reducing or eliminating said symptomatology within 24 to $48 \mathrm{~h}$, which is in accordance with previous preclinical studies $(39,91)$. In fact, the company supplying the product utilized in the present study (Esteripharma S.A. de C.V.) offers products for intranasal (EsteriFlu ${ }^{\circledR}$ ) and buccopharyngeal (Estericide ${ }^{\circledR}$ Bucofaríngeo) applications, as antiseptics that inactivate viruses and eliminate bacteria. However, it is likely that electrolyzed saline, besides having a direct effect on the SARS-CoV-2 virus in the throat, also has an analgesic and regenerative effect on the epithelium at the local level (91). The oral route for electrolyzed saline has already been demonstrated to have no adverse effects in preclinical trials (40). Utilized in pigs to treat porcine epidemic diarrhea virus infection, the symptom duration in infected pigs was markedly shortened and symptom severity was also reduced, producing a much higher survival rate (39). The oral route for aqueous $\mathrm{H}_{2}$, a component of electrolyzed saline, has potent local and systemic anti-inflammatory effects, along with regulating effects on the immune system (30), which may be involved in the mechanism for improving gastrointestinal symptoms.

The administration of electrolyzed saline has been indicated to have positive regulatory effects on the immune 
system in patients with COVID-19, given that its composition is similar to that of the reactive chlorine species and ROS produced by the immune system in mammals, which have been described as mediators and modulators of different physiological processes. Macrophages and neutrophils release ROS to structurally damage invasive pathogens, thus protecting the host against infection (19). In addition, ROS have emerged as a critical second messenger for immune system regulation and the control of exacerbated inflammation or tissue repair via processes of redox signaling (19-23).

Evidence of a direct impact of ROS on the life cycles of viruses is scarce and controversial. Numerous lines of evidence suggest that marked signs of increased production of ROS accompany all respiratory viral infections, which are associated with potentially pathologic processes including cytokine production, inflammation and cell death (92). However, none of the published data are based on direct measurement of ROS levels, but rather on their indirect determination (e.g. quantification of oxidated metabolites, which although is an accepted technique to evaluate ROS concentration, it continues to be an indirect determination) (92). In accordance with the results of the present study, the view that ROS contribute to the suppression of certain respiratory infections through the induction of innate immune responses, including $\mathrm{T}$-cell receptor signaling and T-cell activation, is posited (92).

Examples of mechanisms that support the administration of ROS as beneficial in the fight against viral infections are as follows: i) Influenza virus enhances interferon $\lambda 1$ (IL29) and $\lambda 2 / 3$ (IL28A/IL28B) production via ROS (93). ROS scavenging or suppression of ROS production leads to the inhibition of IFN $\lambda$ synthesis and secretion, and in turn, the enhancement of viral replication (92); ii) signal transducers and activators of transcription (STAT) activation has been indicated to be a relevant event in the response against different viruses (94). ROS formation is involved in STAT activation and the subsequent interferon regulatory factor 1 (IRF-1) and IRF-7 gene expression (95). IRF-1 has been indicated to have a role in shaping innate and adaptive antiviral immunity by inducing the expression of IFN-stimulated genes and mediating signals downstream of IFN- $\gamma(95)$, contributing to the clinical improvement of patients with viral infection (96).

Antioxidant therapies are also known to ameliorate and improve disease outcomes (92). Since electrolyzed saline also contains small amounts of molecular $\mathrm{H}_{2}$, additional antiviral and anti-inflammatory effects, associated to antioxidant mechanisms, may be expected (97). Treatment with molecular antioxidants reduces intracellular levels of influenza virus polymerase, providing a possible mechanism of viral titer reduction in response to antioxidant treatment (98). Additionally, it has been demonstrated that small antioxidant molecules, specifically molecular hydrogen, produce anti-inflammatory effects over multiple COVID-19 target organs, such as the lung, kidney, liver and brain, when compromised by acute and/or chronic diseases (97,99-102). For instance, a study suggested that intraperitoneal administration of hydrogen-rich saline to rats with ischemia/reperfusion-induced acute kidney injury, prevented fibrosis damage and improved renal function (99). The use of a hydrogen-enriched solution during hemodialysis therapies in patients diminished pro-inflammatory markers and prevented complications related to oxidative stress (100).
For the case of the benefits observed in damaged lung, a study performed in mice with chronic lung injury induced by hypoxia/re-oxygenation, demonstrated that inhalation of molecular hydrogen attenuated preexistent lung injuries (101). When 20 patients with asthma or Chronic Obstructive Pulmonary Disease inhaled a $2.4 \%$ hydrogen-containing steam mixed gas (for $45 \mathrm{~min}$ ), attenuation of their inflammatory airway status (decrease of selected pro-inflammatory biomarkers) was observed (102).

In the present study, it was demonstrated that the neutral electrolyzed saline administered is an effective alternative therapy to improve the health and/or prognosis of patients with COVID-19. The different mechanisms of action were also discussed. However, more specific studies regarding each possible mode of action may be performed in order to clearly understand how the electrolyzed saline helps control COVID-19.

The present study had several limitations. First of all, the study was not placebo-controlled and the patients were not blinded. Blood samples were not collected from the control group, preventing the comparison between groups in terms of the progression of the different hematologic and biochemical parameters. There was a correlation between the clinical evaluation and the different laboratory parameters in the experimental group, leading to the supposition that the less favorable clinical conditions in the control group may also be accompanied by equally unfavorable laboratory parameters, but this was not confirmed. In addition, a higher number of inflammation and coagulation markers should be included in future studies, as well as molecular phenotyping of the blood cell strains. Studies with a larger number of patients, both hospitalized and ambulatory, receiving the most effective dose determined in the present study, are also required to confirm the present results.

In conclusion, IV or nebulized administration of electrolyzed saline markedly reduced the symptomatology and risk of disease progression in ambulatory patients with COVID-19. Its administration was well-tolerated and there were no important adverse effects. The treatment effect was mediated by the reduction of inflammation and the apparently increased antiviral immune response, induced by the active species of oxygen and chlorine from the electrolyzed saline that appeared to mimic the effect of physiologic ROS. Further studies are required to confirm those results.

\section{Acknowledgements}

The authors wish to thank Dr Carlos Salazar Silva (Department of Molecular Medicine, School of Medicine, University of Colima, Colima, Mexico) for performing administrative activities necessary for the project and Gusti Gould (freelance translator Spanish to English, Guadalajara, Mexico) for the English language editing of the manuscript.

\section{Funding}

The methodology for serial SARS-CoV-2 detection was funded by the Consejo Estatal de Ciencia y Tecnología del Estado de Colima (grant no. 1, Convocatoria Desafío COVID-19). Esteripharma S.A. de C.V. provided support in the form of 
salaries for authors BPM and ACL. The sponsors had no role in the study design, data collection and analysis or the decision to publish the manuscript.

\section{Availability of data and materials}

The datasets used and/or analyzed in the current study are available from the corresponding author on reasonable request.

\section{Authors' contributions}

IDE, JGE, VM and JPG designed the study and wrote the manuscript. IDE, BAPM and JPG conceived the novel application of electrolyzed saline. CEBS, KAMR, CMR, RLF, MDM, EMZ, JATV, OGDE, JDE, MWG, HRGS, PMD, VM, PJMD, HPM, JMJV and LGG visited the ambulatory patients and administered their medication. CEBS, KAMR, DAMG, CMR, JATV, AEHR, IPRS, DTJ, IGV and VOR performed the biochemical and molecular analyses. VM, FEG, FRL, MJHM, JGE, LMBR, SAZF, PJMD, HPM, JMJV, FGA, LDL, HPGS, MAMH and EPDC performed the clinical evaluations of the patients. EBN, MLMF, MRF, GGS, CRMP and IDE designed and performed the statistical analysis. BAPM and ACL coordinated the production and quality control processes of the experimental therapeutic product. EJDM coordinated and authorized the recruitment of patients at the INSABI Poliforum hospital. JDE was the administrative coordinator of the clinical trial. JDE and JGE checked and approved the authenticity of the raw data. All authors read and approved the final manuscript.

\section{Ethics approval and consent to participate}

The study (registered 2020-01-05) was approved by the ethics committee of the School of Medicine of the Universidad de Colima (Colima, Mexico) and written informed consent was obtained from all participants. All procedures performed in the present protocol were in accordance with the Declaration of Helsinki and the clinical trial was registered as TX-COVID19: RPCEC00000309 in the RPCEC database (05/05/2020).

\section{Patient consent for publication}

Not applicable.

\section{Competing interests}

BAPM and ACL declare that they work for the company Esteripharma, who provided the neutral electrolyzed saline administered in this trial. The company owns a patent for the synthesis of the electrolyzed saline, but had no role in the study design, data collection and analysis or decision to publish the manuscript. Those authors did not participate in the study design, data collection or data analyses. The other authors declare that they have no competing interests.

\section{References}

1. Cascella M, Rajnik M, Cuomo A, Dulebohn SC and Di Napoli R: Features, evaluation and treatment coronavirus (COVID-19). In: StatPearls. Treasure Island (FL), 2020.
2. Caldera-Villalobos C, Garza-Veloz I, Martínez-Avila N, Delgado-Enciso I, Ortiz-Castro Y, Cabral-Pacheco GA and Martinez-Fierro ML: The coronavirus disease (COVID-19) challenge in Mexico: A critical and forced reflection as individuals and society. Front Public Health 8: 337, 2020.

3. O'Keefe JB, Tong EJ, Datoo O'Keefe GA and Tong DC: Predictors of disease duration and symptom course of outpatients with acute covid-19: A retrospective cohort study. medRxiv: 2020.06.05.20123471, 2020.

4. Tenforde MW, Kim SS, Lindsell CJ, Billig Rose E, Shapiro NI, Files DC, Gibbs KW, Erickson HL, Steingrub JS, Smithline HA, et al: Symptom duration and risk factors for delayed return to usual health among outpatients with COVID-19 in a multistate health care systems network-united states, March-June 2020. MMWR Morb Mortal Wkly Rep 69: 993-998, 2020.

5. Wang Y, Zhang D, Du G, Du R, Zhao J, Jin Y, Fu S, Gao L, Cheng Z, Lu Q, et al: Remdesivir in adults with severe COVID-19: A randomised, double-blind, placebo-controlled, multicentre trial. Lancet 395: 1569-1578, 2020.

6. Baqui P, Bica I, Marra V, Ercole A and van der Schaar M: Ethnic and regional variations in hospital mortality from COVID-19 in Brazil: A cross-sectional observational study. Lancet Glob Heal 8: e1018-e1026, 2020.

7. Liang LL, Tseng CH, Ho HJ and Wu CY: Covid-19 mortality is negatively associated with test number and government effectiveness. Sci Rep 10: 12567, 2020.

8. Berumen J, Schmulson M, Alegre-Díaz J, Guerrero G, Larriva-Sahd J, Olaiz G, Wong-Chew RM, Cantú-Brito C, Ochoa-Guzmán A, Garcilazo-Ávila A, et al: Risk of infection and hospitalization by Covid-19 in Mexico: A case-control study. medRxiv: 2020.05.24.20104414, 2020.

9. Rakedzon S, Khoury Y, Rozenberg G and Neuberger A: Hydroxychloroquine and coronavirus disease 2019: A systematic review of a scientific failure. Rambam Maimonides Med J 11: $\mathrm{e} 0025,2020$.

10. Bchetnia M, Girard C, Duchaine C and Laprise C: The outbreak of the novel severe acute respiratory syndrome coronavirus 2 (SARS-CoV-2): A review of the current global status. J Infect Public Health 13: 1601-1610, 2020.

11. Mangalmurti $\mathrm{N}$ and Hunter $\mathrm{CA}$ : Cytokine storms: Understanding COVID-19. Immunity 53: 19-25, 2020.

12. Ucciferri C, Vecchiet J and Falasca K: Role of monoclonal antibody drugs in the treatment of COVID-19. World J Clin Cases 8: 4280-4285, 2020.

13. Ortiz-PradoE,Simbaña-RiveraK,Gómez-BarrenoL,Rubio-NeiraM, Guaman LP, Kyriakidis NC, Muslin C, Jaramillo AMG, Barba-Ostria C, Cevallos-Robalino D, et al: Clinical, molecular, and epidemiological characterization of the SARS-CoV-2 virus and the Coronavirus Disease 2019 (COVID-19), a comprehensive literature review. Diagn Microbiol Infect Dis 98: 115094, 2020.

14. Pence BD: Severe COVID-19 and aging: Are monocytes the key? Geroscience 42: 1051-1061, 2020.

15. Huang W, Berube J, McNamara M, Saksena S, Hartman M, Arshad T, Bornheimer SJ and O'Gorman M: Lymphocyte subset counts in COVID-19 patients: A meta-analysis. Cytometry A 97: 772-776, 2020.

16. Henry BM, de Oliveira MHS, Benoit S, Plebani M and Lippi G: Hematologic, biochemical and immune biomarker abnormalities associated with severe illness and mortality in coronavirus disease 2019 (COVID-19): A meta-analysis. Clin Chem Lab Med 58: 1021-1028, 2020.

17. Kono N: Superoxidized electrolyzed solution of neutral $\mathrm{pH}$ and uses there of., 2015.

18. Li R, Jia Z and Trush MA: Defining ROS in biology and medicine. React Oxyg Species (Apex) 1: 9-21, 2016.

19. Forrester SJ, Kikuchi DS, Hernandes MS, Xu Q and Griendling KK: Reactive oxygen species in metabolic and inflammatory signaling. Circ Res 122: 877-902, 2018.

20. Tan HY, Wang N, Li S, Hong M, Wang X and Feng Y: The reactive oxygen species in macrophage polarization: Reflecting its dual role in progression and treatment of human diseases. Oxid Med Cell Longev 2016: 2795090, 2016.

21. George-Chandy A, Nordström I, Nygren E, Jonsson IM, Postigo J, Collins LV and Eriksson K: Th17 development and autoimmune arthritis in the absence of reactive oxygen species. Eur J Immunol 38: 1118-1126, 2008.

22. Kuhns DB, Alvord WG, Heller T, Feld JJ, Pike KM, Marciano BE, Uzel G, DeRavin SS, Priel DA, Soule BP, et al: Residual NADPH oxidase and survival in chronic granulomatous disease. N Engl J Med 363: 2600-2610, 2010. 
23. Schieber M and Chandel NS: ROS function in redox signaling and oxidative stress. Curr Biol 24: R453-R462, 2014.

24. Calabrese EJ, Giordano JJ, Kozumbo WJ, Leak RK and Bhatia TN: Hormesis mediates dose-sensitive shifts in macrophage activation patterns. Pharmacol Res 137: 236-249, 2018

25. Mills EL and O'Neill LA: Reprogramming mitochondrial metabolism in macrophages as an anti-inflammatory signal. Eur J Immunol 46: 13-21, 2016.

26. Prokopowicz ZM, Arce F, Biedroń R, Chiang CL, Ciszek M Katz DR, Nowakowska M, Zapotoczny S, Marcinkiewicz J and Chain BM: Hypochlorous acid: A natural adjuvant that facilitates antigen processing, cross-priming, and the induction of adaptive immunity. J Immunol 184: 824-835, 2010.

27. Reth M: Hydrogen peroxide as second messenger in lymphocyte activation. Nat Immunol 3: 1129-1134, 2002.

28. Li Z, Xu X, Leng X, He M, Wang J, Cheng S and Wu H: Roles of reactive oxygen species in cell signaling pathways and immune responses to viral infections. Arch Virol 162: 603-610, 2017.

29. Ge L, Yang M, Yang NN, Yin XX and Song WG: Molecular hydrogen: A preventive and therapeutic medical gas for various diseases. Oncotarget 8: 102653-102673, 2017.

30. Lin CP, Chuang WC, Lu FJ and Chen CY: Anti-oxidant and anti-inflammatory effects of hydrogen-rich water alleviate ethanol-induced fatty liver in mice. World J Gastroenterol 23 4920-4934, 2017.

31. Moher D, Hopewell S, Schulz KF, Montori V, Gøtzsche PC Devereaux PJ, Elbourne D, Egger M and Altman DG; CONSORT: CONSORT 2010 explanation and elaboration: Updated guidelines for reporting parallel group randomised trials. Int J Surg 10: $28-55,2012$.

32. Freites-Martinez A, Santana N, Arias-Santiago S and Viera A Using the common terminology criteria for adverse events (CTCAE-version 5.0) to evaluate the severity of adverse events of anticancer therapies. Actas Dermosifiliogr (Engl Ed) 112: 90-92, 2021 (In English, Spanish).

33. Gouveia BG, Rijo P, Gonçalo TS and Reis CP: Good manufacturing practices for medicinal products for human use. J Pharm Bioallied Sci 7: 87-96, 2015.

34. Rogatko A, Cook-Wiens G, Tighiouart M and Piantadosi S Escalation with overdose control is more efficient and safer than accelerated titration for dose finding. Entropy (Basel) 17: 5288-5303, 2015

35. American College of Allergy A and I: No Title. A Messag to Asthma Suff About a Short Albuterol Metered Dose Inhalers: $1,2020$.

36. British Lung Foundation: No Title. What is Soc Shield who needs to do this? 1, 2020.

37. Asthma Society of Ireland: No Title. Coronavirus (COVID-19) Advice: $1,2020$.

38. British thoracic society: No Title. COVID-19 Inf Respir community: 1, 2020 .

39. Watson RD: Oral administration of electrolyzed water for treatment and prevention of PEDv in swine, swine herds and swine confinements. US Patent 20140287065 A1. Filed March 14, 2013; issued February 24, 2014.

40. Morita C, Nishida T and Ito K: Biological toxicity of acid electrolyzed functional water: Effect of oral administration on mouse digestive tract and changes in body weight. Arch Oral Biol 56: $359-366,2011$

41. Cohen DR, Todd S, Gregory WM and Brown JM: Adding a treatment arm to an ongoing clinical trial: A review of methodology and practice. Trials 16: 179, 2015.

42. Yorganci E, Evans CJ, Johnson H, Barclay S, Murtagh FE, Yi D, Gao W, Pickles A and Koffman J: Understanding usual care in randomised controlled trials of complex interventions: A multi-method approach. Palliat Med 34: 667-679, 2020.

43. Dawson L, Zarin DA, Emanuel EJ, Friedman LM, Chaudhari B and Goodman SN: Considering usual medical care in clinical trial design. PLoS Med 6: e1000111, 2009.

44. Hinks TSC, Barber VS, Black J, Dutton SJ, Jabeen M, Melhorn J, Rahman NM, Richards D, Lasserson D, Pavord ID and Bafadhel M: A multi-centre open-label two-arm randomised superiority clinical trial of azithromycin versus usual care in ambulatory COVID-19: Study protocol for the ATOMIC2 trial. Trials 21: 718, 2020

45. Sterne JAC, Diaz J, Villar J, Murthy S, Slutsky AS, Perner A, Jüni P, Angus DC, Annane D, Azevedo LCP, et al: Corticosteroid therapy for critically ill patients with COVID-19: A structured summary of a study protocol for a prospective meta-analysis of randomized trials. Trials 21: 734, 2020.
46. Kvien TK, Heiberg T and Hagen KB: Minimal clinically important improvement/difference (MCII/MCID) and patient acceptable symptom state (PASS): What do these concepts mean? Ann Rheum Dis 66 (Suppl 3): iii40-iii41, 2007.

47. Fei JZ, Perruccio AV, Ye JY, Gladman DD and Chandran V: The relationship between patient acceptable symptom state and disease activity in patients with psoriatic arthritis. Rheumatology (Oxford) 59: 69-76, 2019.

48. Delgado-Enciso I, Valtierra-Alvarez J, Paz-Garcia J, PreciadoRamirez J, Soriano-Hernandez AD, Mendoza-Hernandez MA, Guzman-Esquivel J, Cabrera-Licona A, Delgado-Enciso J, Cortes-Bazan JL, et al: Patient-reported health outcomes for severe knee osteoarthritis after conservative treatment with an intra-articular cell-free formulation for articular cartilage regeneration combined with usual medical care vs. usual medical care alone: A randomized co. Exp Ther Med 17: 3351-3360, 2019.

49. Coates LC, Tillett W, Shaddick G, Pincus T, Kavanaugh A and Helliwell PS: Value of the routine assessment of patient index data 3 in patients with psoriatic arthritis: Results from a tight-control clinical trial and an observational cohort. Arthritis Care Res (Hoboken) 70: 1198-1205, 2018.

50. Delgado-Enciso I, Paz-Garcia J, Valtierra-Alvarez J, Preciado-Ramirez J, Almeida-Trinidad R, Guzman-Esquivel J, Mendoza-Hernandez MA, Garcia-Vega A, SorianoHernandez AD, Cortes-Bazan JL, et al: A phase I-II controlled randomized trial using a promising novel cell-free formulation for articular cartilage regeneration as treatment of severe osteoarthritis of the knee. Eur J Med Res 23: 52, 2018.

51. Delgado-Enciso I, Paz-Michel B, Melnikov V, Guzman-Esquivel J, Espinoza-Gomez F, Soriano-Hernandez AD, Rodriguez-Sanchez IP, Martinez-Fierro ML, Ceja-Espiritu G, Olmedo-Buenrostro BA, et al: Smoking and female sex as key risk factors associated with severe arthralgia in acute and chronic phases of chikungunya virus infection. Exp Ther Med 15: 2634-2642, 2018

52. Skipper CP, Pastick KA, Engen NW, Bangdiwala AS, Abassi M, Lofgren SM, Williams DA, Okafor EC, Pullen MF, Nicol MR, et al: Hydroxychloroquine in nonhospitalized adults with early COVID-19: A randomized trial. Ann Intern Med 173: 623-631, 2020

53. Salepci E, Turk B, Ozcan SN, Bektas ME, Aybal A, Dokmetas I and Turgut S: Symptomatology of COVID-19 from the otorhinolaryngology perspective: A survey of 223 SARS-CoV-2 RNA-positive patients. Eur Arch Otorhinolaryngol 278: 525-535, 2021.

54. Rivett L, Sridhar S, Sparkes D, Routledge M, Jones NK, Forrest S, Young J, Pereira-Dias J, Hamilton WL, Ferris M, et al: Screening of healthcare workers for SARS-CoV-2 highlights the role of asymptomatic carriage in COVID-19 transmission. Elife 9: e58728, 2020.

55. Englbrecht M, Tarner IH, van der Heijde DM, Manger B, Bombardier $\mathrm{C}$ and Müller-Ladner U: Measuring pain and efficacy of pain treatment in inflammatory arthritis: A systematic literature review. J Rheumatol (Suppl 90): 3-10, 2012.

56. Tubach F, Ravaud P, Baron G, Falissard B, Logeart I, Bellamy N, Bombardier C, Felson D, Hochberg M, van der Heijde D and Dougados M: Evaluation of clinically relevant changes in patient reported outcomes in knee and hip osteoarthritis: The minimal clinically important improvement. Ann Rheum Dis 64: 29-33, 2005.

57. Khanna D, Pope JE, Khanna PP, Maloney M, Samedi N, Norrie D, Ouimet G and Hays RD: The minimally important difference for the fatigue visual analog scale in patients with rheumatoid arthritis followed in an academic clinical practice. J Rheumatol 35: 2339-2343, 2008

58. Johnson MJ, Close L, Gillon SC, Molassiotis A, Lee PH and Farquhar MC; Breathlessness Research Interest Group (BRIG): Use of the modified borg scale and numerical rating scale to measure chronic breathlessness: A pooled data analysis. Eur Respir J 47: 1861-1864, 2016.

59. Meza-Robles C, Barajas-Saucedo CE, Tiburcio-Jimenez D, Mokay-Ramírez KA, Melnikov V, Rodriguez-Sanchez IP, Martinez-Fierro ML, Garza-Veloz I, Zaizar-Fregoso SA, Guzman-Esquivel J, et al: One-step nested RT-PCR for COVID-19 detection: A flexible, locally developed test for SARS-CoV2 nucleic acid detection. J Infect Dev Ctries 14: 679-684, 2020

60. Ferrari D, Lombardi G, Strollo M, Pontillo M, Motta A and Locatelli M: A possible antioxidant role for vitamin D in soccer players: A retrospective analysis of psychophysical stress markers in a professional team. Int J Environ Res Public Health 17: 3484, 2020. 
61. Singh A, Sood N, Narang V and Goyal A: Morphology of COVID-19-affected cells in peripheral blood film. BMJ Case Rep 13: e236117, 2020.

62. Lüke F, Orsó E, Kirsten J, Poeck H, Grube M, Wolff D, Burkhardt R, Lunz D, Lubnow M, Schmidt B, et al: Coronavirus disease 2019 induces multi-lineage, morphologic changes in peripheral blood cells. EJHaem, Jun 29, 2020 (Online ahead of print).

63. El Comentario U de C: No Title. Graves, 200 pacientes Hosp con Covid-19; hay 21 intubados.

64. Vickers AJ: The use of percentage change from baseline as an outcome in a controlled trial is statistically inefficient: A simulation study. BMC Med Res Methodol 1: 6, 2001.

65. McNutt LA, Wu C, Xue X and Hafner JP: Estimating the relative risk in cohort studies and clinical trials of common outcomes. Am J Epidemiol 157: 940-943, 2003.

66. Wacholder S: Binomial regression in GLIM: Estimating risk ratios and risk differences. Am J Epidemiol 123: 174-184, 1986.

67. Diaz-Quijano FA: A simple method for estimating relative risk using logistic regression. BMC Med Res Methodol 12: 14, 2012.

68. HyLown Consulting LLC: Power and sample size HomeCalculators compare 2 proportions: 2-Sample, 1-Sided. Calculator: 1, 2013.

69. Wang L: C-reactive protein levels in the early stage of COVID-19. Med Mal Infect 50: 332-334, 2020.

70. Alzaid F, Julla JB, Diedisheim M, Potier C, Potier L, Velho G, Gaborit B, Manivet P, Germain S, Vidal-Trecan T, et al: Monocyte class switch and hyperinflammation characterise severe COVID-19 in type 2 diabetes. medRxiv: 2020.06.02.20119909, 2020 .

71. Zhang D, Guo R, Lei L, Liu H, Wang Y, Wang Y, Qian F, Dai T, Zhang T, Lai Y, et al: COVID-19 infection induces readily detectable morphological and inflammation-related phenotypic changes in peripheral blood monocytes, the severity of which correlate with patient outcome. medRxiv: 2020.03.24.20042655, 2020 .

72. McKechnie JL and Blish CA: The innate immune system: Fighting on the front lines or fanning the flames of COVID-19? Cell Host Microbe 27: 863-869, 2020.

73. He R, Lu Z, Zhang L, Fan T, Xiong R, Shen X, Feng H, Meng H, Lin W, Jiang W and Geng Q: The clinical course and its correlated immune status in COVID-19 pneumonia. J Clin Virol 127: 104361, 2020.

74. National Research Project for SARS, Beijing Group: The involvement of natural killer cells in the pathogenesis of severe acute respiratory syndrome. Am J Clin Pathol 121: 507-511, 2004.

75. Zhao Q, Meng M, Kumar R, Wu Y, Huang J, Deng Y, Weng Z and Yang L: Lymphopenia is associated with severe coronavirus disease 2019 (COVID-19) infections: A systemic review and meta-analysis. Int J Infect Dis 96: 131-135, 2020.

76. Yang X, Yang Q, Wang Y, Wu Y, Xu J, Yu Y and Shang Y: Thrombocytopenia and its association with mortality in patients with COVID-19. J Thromb Haemost 18: 1469-1472, 2020.

77. Margraf A and Zarbock A: Platelets in inflammation and resolution. J Immunol 203: 2357-2367, 2019.

78. Taneja V: Sex hormones determine immune response. Front Immunol 9: 1931, 2018.

79. Pozzilli P and Lenzi A: Commentary: Testosterone, a key hormone in the context of COVID-19 pandemic. Metabolism 108: $154252,2020$.

80. Tan T, Khoo B, Mills EG, Phylactou M, Patel B, Eng PC, Thurston L, Muzi B, Meeran K, Prevost AT, et al: Association between high serum total cortisol concentrations and mortality from COVID-19. Lancet Diabetes Endocrinol 8: 659-660, 2020.

81. Merad M and Martin JC: Pathological inflammation in patients with COVID-19: A key role for monocytes and macrophages. Nat Rev Immunol 20: 355-362, 2020.

82. Bateman L, Rao P, Jones TH and Kelly DM: SAT-049 testosterone therapy reduces inflammatory activation of human monocytes in hypogonadal type-2 diabetic men as a potential mechanism to improve atherosclerosis. J Endocr Soc 4 (Suppl 1): SAT-049, 2020.

83. Milush J: Role of monocyte oxidative stress and mineralocorticoid receptor signaling on cardiovascular disease and persistent inflammation in antiretroviral-treated HIV+ persons. Grantome 1,2015.

84. Gomez-Sanchez E and Gomez-Sanchez CE: The multifaceted mineralocorticoid receptor. Compr Physiol 4: 965-994, 2014
85. Uchida MC, Bacurau RFP, Navarro F, Pontes FL Jr, Tessuti VD, Moreau RL, Rosa LFBPC and Aoki MS: Alteração da relação testosterona: Cortisol induzida pelo treinamento de força em mulheres. Rev Bras Med Esporte 10: 165-168, 2004.

86. Block MS and Rowan BG: Hypochlorous acid: A review. J Oral Maxillofac Surg 78: 1461-1466, 2020.

87. Montesinos-Peña NE, Hernández-Valencia M, Delgado-Enciso I and Herrera-Leal A, Paz-Michel BA: Evaluation of an antiseptic gel of intravaginal application for multitreated patients for infectious cervicovaginitis. Ginecol Obs Mex 87: 454-466, 2019.

88. Cabello GC, Rosete ODP and Manjarrez ZME: Efecto de una solución electrolizada de superoxidación con pH neutro sobre la infección del virus de influenza A en células MDCK. Rev Inst Nal Enf Resp Mex 22: 280-287, 2009.

89. Takeda Y, Uchiumi H, Matsuda S and Ogawa H: Acidic electrolyzed water potently inactivates SARS-CoV-2 depending on the amount of free available chlorine contacting with the virus. Biochem Biophys Res Commun 530: 1-3, 2020.

90. Moorman E, Montazeri N and Jaykus LA: Efficacy of neutral electrolyzed water for inactivation of human norovirus. Appl Environ Microbiol 83: e00653-17, 2017.

91. García JP, Maldonado RA, Díaz RI, Muñiz J and Rodríguez HA Sustitución del uso de solución salina fi siológica como irrigante en el manejo de pacientes sépticos y quirúrgicos por solución electrolizada. Rev Mex Cir Bucal Maxilofac 7: 46-52, 2011.

92. Khomich OA, Kochetkov SN, Bartosch B and Ivanov AV: Redox biology of respiratory viral infections. Viruses 10: 392, 2018

93. Kim HJ, Kim CH, Ryu JH, Kim MJ, Park CY, Lee JM, Holtzman MJ and Yoon JH: Reactive oxygen species induce antiviral innate immune response through IFN- $\lambda$ regulation in human nasal epithelial cells. Am J Respir Cell Mol Biol 49: $855-865,2013$

94. Delgado-Enciso I, López-Lemus AU, Valcarcel-Gamiño AJ, Rodriguez-Sanchez IP, Valle-Reyes S, Martinez-Fierro ML, Melnikov V, Guzmán-Esquivel J, Vaca-Paniagua $F$, Valdez-Velazquez LL, et al: Dengue virus-1 NS5 genetic variant associated with a severe clinical infection: Possible reduction of the innate immune response by inhibition of interferon type 1 and the Janus kinase-signal transducer and activator of transcription signaling pathway. Int J Mol Med 41: 2263-2269, 2018

95. Liu T, Castro S, Brasier AR, Jamaluddin M, Garofalo RP and Casola A: Reactive oxygen species mediate virus-induced STAT activation: Role of tyrosine phosphatases. J Biol Chem 279: 2461-2469, 2004

96. Nair S, Poddar S, Shimak RM and Diamond MS: Interferon regulatory factor 1 protects against chikungunya virus-induced immunopathology by restricting infection in muscle cells. J Virol 91: e01419-17, 2017.

97. Hong Y, Chen S and Zhang JM: Hydrogen as a selective antioxidant: A review of clinical and experimental studies. J Int Med Res 38: 1893-1903, 2010.

98. Pyo CW, Shin N, Jung K, Choi JH and Choi SY: Alteration of copper-zinc superoxide dismutase 1 expression by influenza A virus is correlated with virus replication. Biochem Biophys Res Commun 450: 711-716, 2014

99. Chen J, Zhang H, Hu J, Gu Y, Shen Z, Xu L, Jia X, Zhang X and Ding $X$ : Hydrogen-rich saline alleviates kidney fibrosis following AKI and retains klotho expression. Front Pharmacol 8: 499, 2017.

100. Nakayama M, Kabayama S and Ito S: The hydrogen molecule as antioxidant therapy: Clinical application in hemodialysis and perspectives. Ren Replace Ther 2: 23, 2016.

101. Chen M, Zhang J, Chen Y, Qiu Y, Luo Z, Zhao S, Du L and Tian D: Hydrogen protects lung from hypoxia/re-oxygenation injury by reducing hydroxyl radical production and inhibiting inflammatory responses. Sci Rep 8: 8004, 2018.

102. Wang ST, Bao C, He Y, Tian X, Yang Y, Zhang T and Xu KF: Hydrogen gas (XEN) inhalation ameliorates airway inflammation in asthma and COPD patients. QJM 113: 870-875, 2020.

This work is licensed under a Creative Commons Attribution-NonCommercial-NoDerivatives 4.0 International (CC BY-NC-ND 4.0) License. 